\title{
TECHNOLOGIES TO ENHANCE THE OPERATION OF EXISTING NATURAL GAS COMPRESSION INFRASTRUCTURE
}

\author{
Quarterly Technical Progress Report \\ Reporting Period Start Date: 07/01/05 \\ Reporting Period End Date: 09/30/05
}

\author{
Prepared by \\ Anthony J. Smalley \\ Ralph E. Harris \\ Gary D. Bourn \\ Danny M. Deffenbaugh
}

DOE Award No. DE-FC26-02NT41646

SwRI ${ }^{\circledR}$ Project No. 18.06223

\author{
Prepared for \\ U.S. Department of Energy \\ National Energy Technology Laboratory \\ 3610 Collins Ferry Road \\ P.O. Box 880 \\ Morgantown, WV 26507-0880
}

October 27, 2005

SOUTHWEST RESEARCH INSTITUTE 


\title{
TECHNOLOGIES TO ENHANCE THE OPERATION OF EXISTING NATURAL GAS COMPRESSION INFRASTRUCTURE
}

\author{
Quarterly Technical Progress Report \\ Reporting Period Start Date: 07/01/05 \\ Reporting Period End Date: 09/30/05 \\ Prepared by \\ Anthony J. Smalley \\ Ralph E. Harris \\ Gary D. Bourn \\ Danny M. Deffenbaugh
}

DOE Award No. DE-FC26-02NT41646

SwRI ${ }^{\circledR}$ Project No. 18.06223

Prepared for

U.S. Department of Energy

National Energy Technology Laboratory

3610 Collins Ferry Road

P.O. Box 880

Morgantown, WV 26507-0880

October 27, 2005

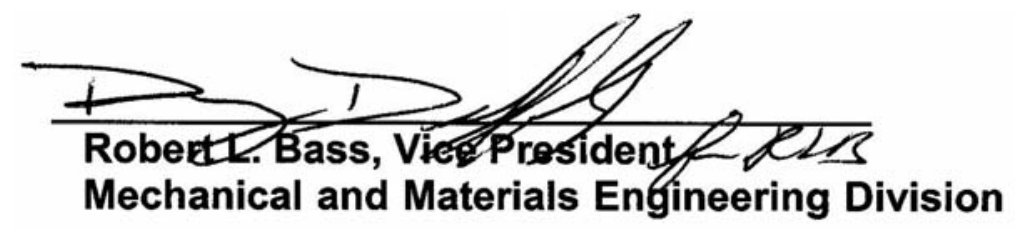

SOUTHWEST RESEARCH INSTITUTE 


\section{DISCLAIMER}

This report was prepared as an account of work sponsored by an agency of the United States Government. Neither the United States nor any agency thereof, nor any of their employees, makes any warranty, express or implied, or assumes any legal liability or responsibility for the accuracy, completeness, or usefulness of any information, apparatus, product, or process disclosed, or represents that its use would not infringe privately owned rights. Reference herein to any specific commercial product, process, or service by trade name, trademark, manufacturer, or otherwise does not necessarily constitute or imply its endorsement, recommendation, or favoring by the United States Government or any agency thereof. The views and opinions of authors expressed herein do not necessarily state or reflect those of the United States Government or any agency thereof. 


\section{ABSTRACT}

This quarterly report documents work performed under Tasks 15, 16, and 18 through 23 of the project entitled: Technologies to Enhance the Operation of Existing Natural Gas Compression Infrastructure. The project objective is to develop and substantiate methods for operating integral engine/compressors in gas pipeline service, which reduce fuel consumption, increase capacity, and enhance mechanical integrity. The report first summarizes key results from survey site tests performed on an HBA-6 installed at Duke Energy's Bedford compressor station, and on a TCVC10 engine/compressor installed at Dominion's Groveport Compressor Station. The report then presents results of design analysis performed on the Bedford HBA-6 to develop options and guide decisions for reducing pulsations and enhancing compressor system efficiency and capacity. The report further presents progress on modifying and testing the laboratory GMVH6 at SwRI for correcting air imbalance. 


\section{TABLE OF CONTENTS}

Section

Page

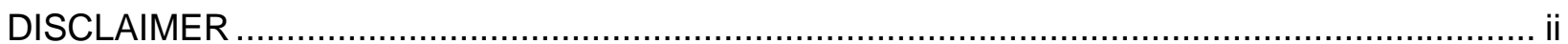

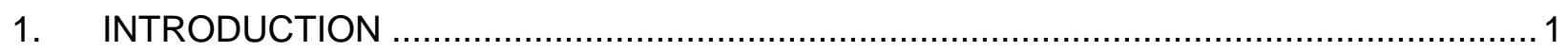

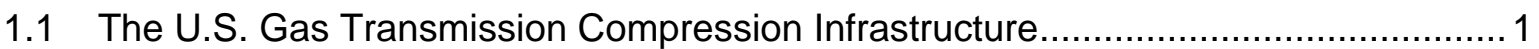

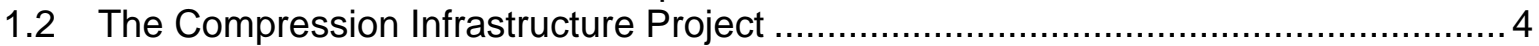

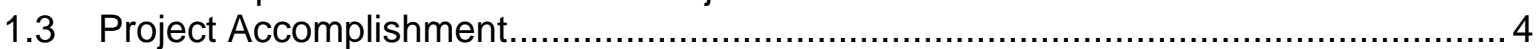

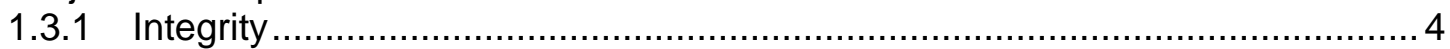

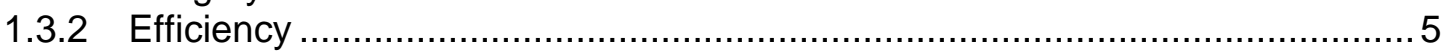

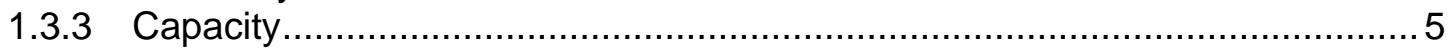

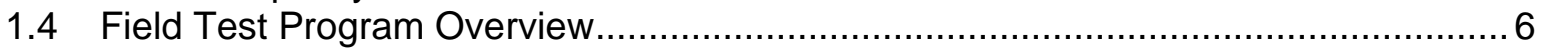

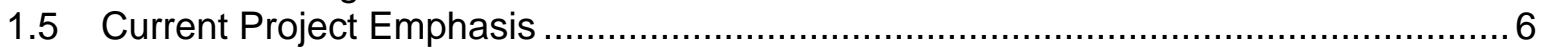

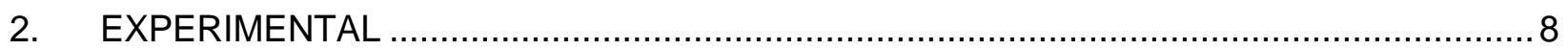

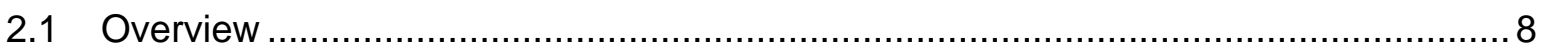

2.2 Sensors and Data Channels for Field Measurement ........................................ 8

2.3 Potential Instrument Changes for Compressor Side Testing ............................... 11

2.4 Laboratory GMVH Measurements for Air Balance Tasks .................................... 12

2.5 Computational Modeling for Air Balance Investigation...................................... 16

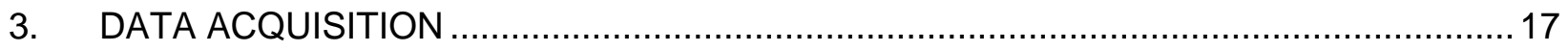

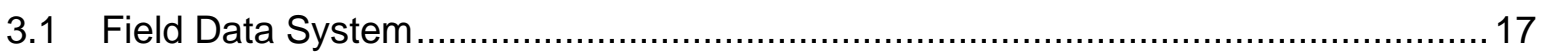

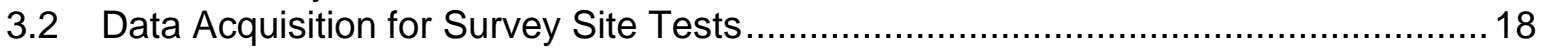

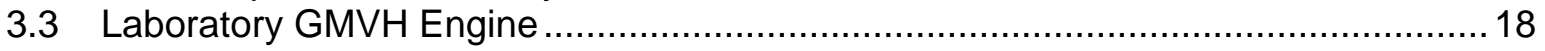

4. RESULTS AND DISCUSSION: SITE TEST SUMMARY AND HBA-6 DESIGN

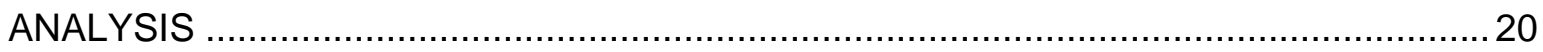

4.1 Overview and Background to Survey Tests .................................................... 20

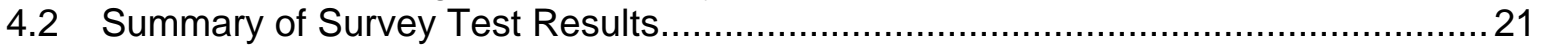

4.3 Design Analysis for the HBA-6 at Bedford Station ........................................ 25

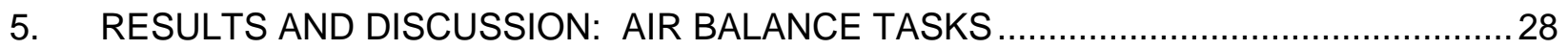

5.1 Overview and Background of Air Balance Tasks .............................................. 28

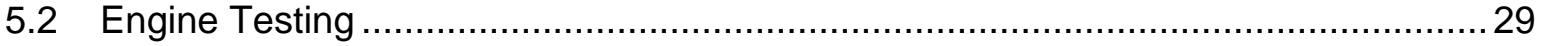

5.3 Demonstration of Side Branch Absorber....................................................... 32

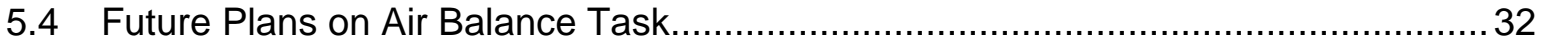

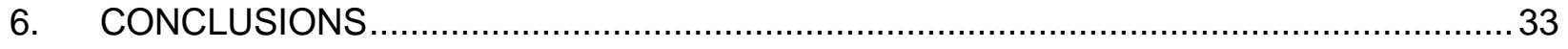

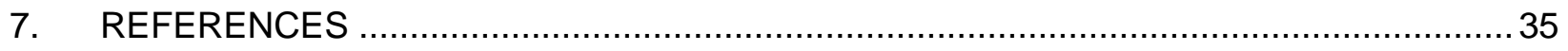

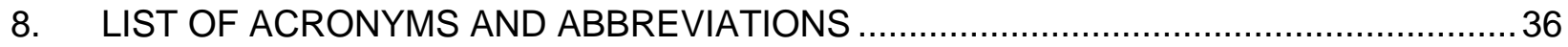




\section{LIST OF FIGURES}

Figure

Page

Figure 1-1 TLA6 (2,000 HP) and GMW10 (2,500 HP) in Pipeline Service ......................... 1

Figure 1-2 Install Dates: Over 50\% of Pipeline Compressors Exceed 40 Years Old............. 2

Figure 1-3 Industry Fuel Consumption ( 7.7 MCF/HP-Hr $\pm 20 \%$ - Need to Lower the

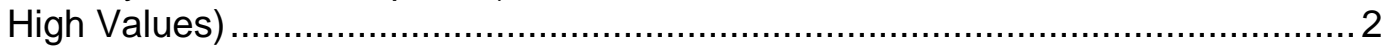

Figure 1-4 Compressor Thermal Efficiency Histogram Based on GMRC Survey.................. 3

Figure 1-5 Integrity: Crankshaft Failure Examples - Need Methods of Avoidance ............... 3

Figure 2-1 Photograph of Dynamic Exhaust Pressure Sensor in Exhaust Plenum .............. 13

Figure 2-2 Photographs of GMVH Cylinder Flow Bench .......................................... 15

Figure 2-3 Current GMVH Computational Model Schematic ....................................... 16

Figure 3-1 Front View of Field Data Acquisition System (DAS) ..................................... 17

Figure 3-2 Rear View of Field Data Acquisition System (DAS) .................................... 17

Figure 3-3 Laboratory GMVH Instrumentation and Control Panel .................................. 19

Figure 4-1 Overview Photograph of HBA-6 Unit (Duke Energy's Bedford Station;

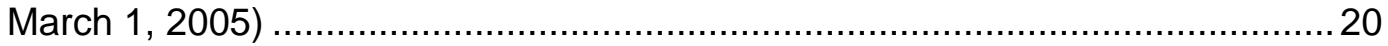

Figure 4-2 Overview Photograph of TCVC10 Unit (Dominion's Groveport Station; April

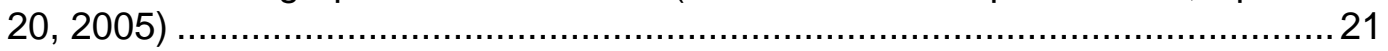

Figure 4-3 Comparison of Enthalpy and DIP Based Efficiency for Bedford and

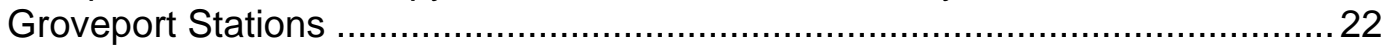

Figure 4-4 Comparison of Valve DIP and Total DIP Loss for Groveport and Bedford

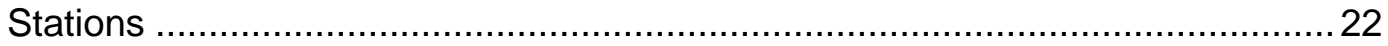

Figure 4-5 Comparison of Suction Nozzle Pulsations; Groveport and Bedford ....................23

Figure 4-6 Comparison of Discharge Nozzle Pulsations; Groveport and Bedford................23

Figure 4-7 Comparison of Suction Lateral Pulsations; Groveport and Bedford ...................24

Figure 4-8 Comparison of Discharge Lateral Pulsations; Groveport and Bedford...............24

Figure 4-9 Original Pulsations (red) Compared to Pulsations with Modified Bottle

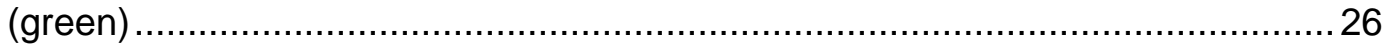

Figure 4-10 Modified Suction Bottle Design .............................................................. 26

Figure 4-11 Configuration Schematic for Side Branch Absorber ................................... 27

Figure 4-12 Comparison of Original Pulsations with Predicted Pulsations (red) After

Addition of Side Branch Absorber (green) ............................................... 27

Figure 5-1 100-Cycle Average Cylinder Pressures at 20 Degrees BTDC versus Air

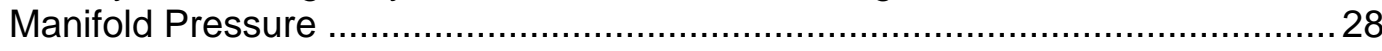

Figure 5-2 100-Cycle Average Cylinder Pressures at 20 Degrees BTDC versus Air Manifold Pressure - Post Power Assembly Swap..................................... 30

Figure 5-3 Cylinder Pressures at 20 Degrees BTDC for Air Manifold Pressure of 20 inHg - Before and After Power Assembly Swap .............................................. 30

Figure 5-4 Schematic of Intake Manifold Dynamic Flow Measurements ............................. 31

Figure 5-5 Cylinder Pressures and Pitot Delta-Pressure for Cylinders $1 \mathrm{~L}$ and $3 \mathrm{~L}$ at

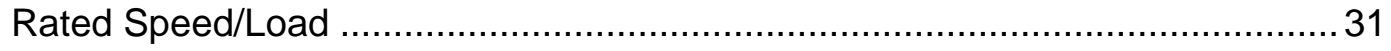

Figure 5-6 Final Design of the Exhaust Side Branch Absorber .................................. 32 


\section{LIST OF TABLES}

$\underline{\text { Table }}$

Page

Table 2-1 Time-Averaged and Crank-Angle Resolved Measurements on GMVH .............13

Table 2-2 Static Measurements on Each Cylinder of GMVH..................................... 14

Table 2-3 GMVH Cylinder Flow Bench Measurements ............................................ 16 


\section{INTRODUCTION}

This quarterly report summarizes results from survey site tests on two integral engine compressors, an HBA-6 and a TCVC10. These tests support the program goal of identifying and reducing losses in U.S. natural gas transmission compressor installations, thereby reducing fuel consumption and improving capacity of units operating at their power limit. In addition, the report presents design analysis on the compressor manifold of the HBA-6 tested. This design analysis has developed options and guided decisions on modifications to reduce pulsations, enhance thermal efficiency, and increase compressor capacity. The report also presents progress on the installation of changes to a laboratory GMVH6 engine, aimed at controlling air balance and air manifold dynamics.

\subsection{THE U.S. GAS TRANSMISSION COMPRESSION INFRASTRUCTURE}

The gas transmission industry operates over 4,000 integral engine compressors, which play a major role in pumping natural gas through the U.S. pipeline system. Although the use of centrifugal compressors in the U.S. pipeline industry has grown, these integral reciprocating units still represent over $70 \%$ of the fleet in numbers and over one-half of the installed power. These "slow-speed" integral engine compressors have been the workhorses of the industry for over 50 years, providing the reliable gas compression needed by the pipeline system. Figure 1-1 shows two such units: a 48-year old TLA6 and a 50-year old GMW10.
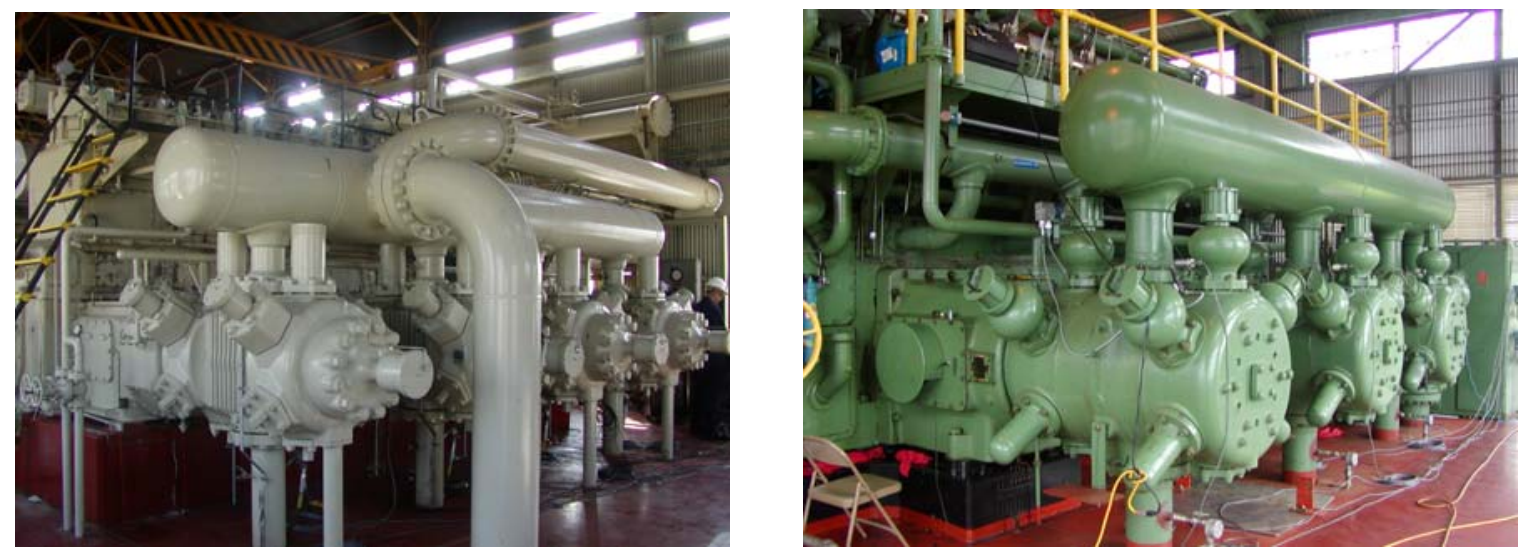

Figure 1-1. TLA6 (2,000 HP) and GMW10 (2,500 HP) in Pipeline Service

Figure 1-2 shows the age distribution of the current infrastructure. Over one-half of the fleet is well over 40 years old, but replacing all these units with currently available technology would incur a huge cost and disruption to service with insufficient improvement in overall performance of the pipeline system to justify this cost and disruption. For these reasons, wholesale replacement remains unlikely (although selective replacement driven by factors such as environmental regulations can be expected). Growth to a 30-TCF-plus gas market in the U.S., anticipated over the next 10 to 20 years, must come on the backs of the existing compression infrastructure; therefore, it will depend on continued integrity, enhanced capacity, and efficiency of the existing integral engine/compressors under all loads. The industry needs demonstrated 
technology options and operating methods, which will cost-effectively maximize the capacity of these old units, and reduce their fuel consumption, while respecting or improving their integrity.

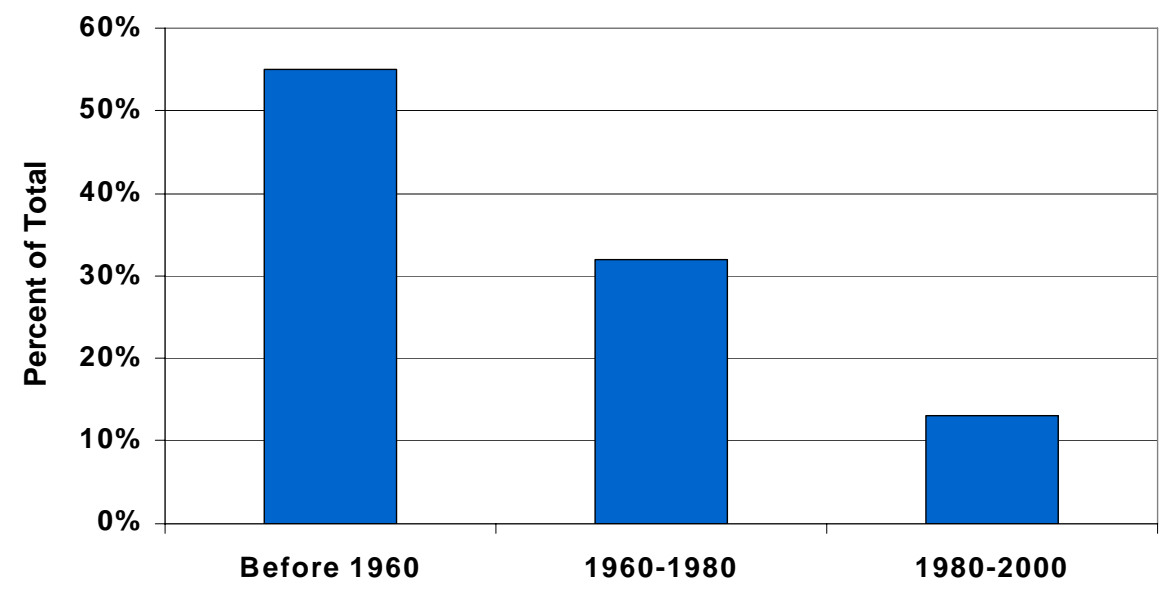

Figure 1-2. Install Dates: Over 50\% of Pipeline Compressors Exceed 40 Years Old

Figure 1-3, Figure 1-4, and Figure 1-5 exemplify these needs of the existing infrastructure.

Figure 1-3 shows how annual fuel consumption at a number of individual compressor stations in the pipeline system varies with the number of horsepower hours delivered by the engine to the compressor cylinders at that station. Points on the high side of the mean slope represent stations, which are burning more than the industry average. In addition, with a regressed slope of 7.7 CF/BHP-Hr for Figure 1-3, the industry burns significantly more fuel than the most efficient current technology natural gas engines (as little as $6 \mathrm{CF} / \mathrm{BHP}-\mathrm{Hr}$ ). As a slightly different performance measure for the industry, Smalley, et al. [1], calculated an industry average (ratio of total fuel volume to total BHP-Hr) of 8.25 SCF/BHP-Hr.

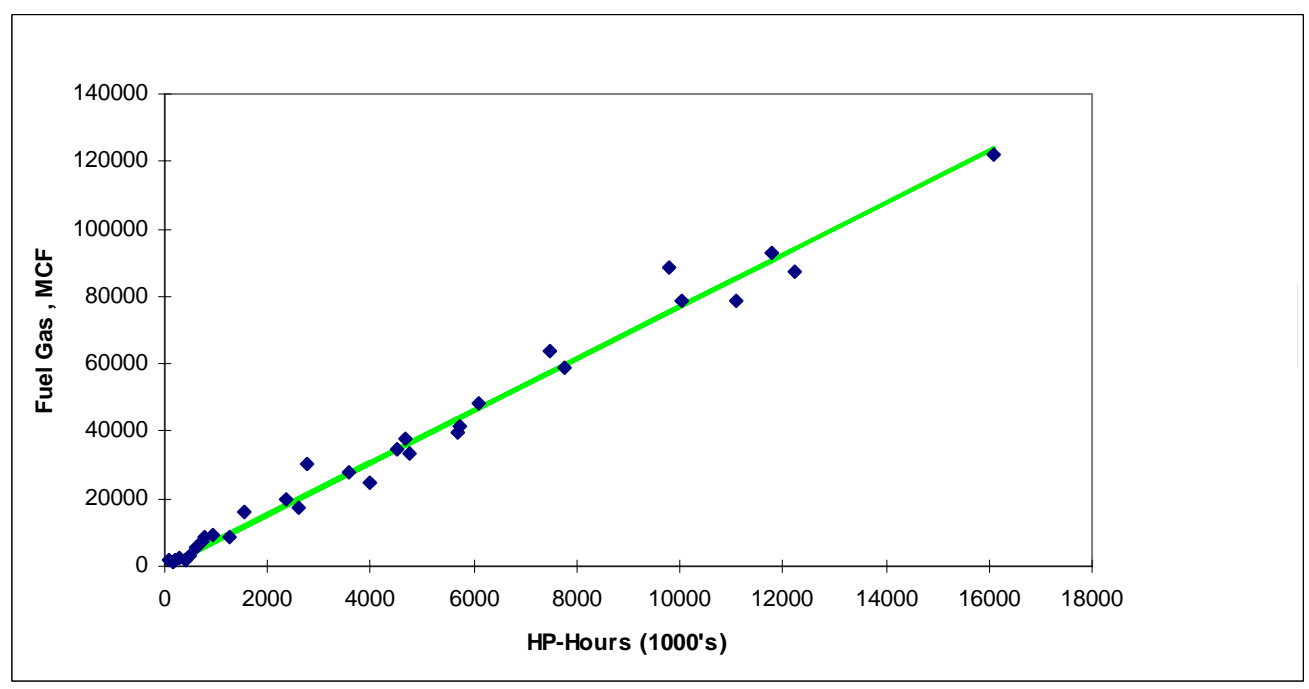

Figure 1-3. Industry Fuel Consumption

( 7.7 MCF/HP-Hr $\pm \mathbf{2 0 \%}$ - Need to Lower the High Values)

SwRI Project 18.06223; DOE Award No. DE-FC26-02NT41646 
Figure 1-4 presents a distribution of compressor thermal efficiency for the industry created by the Gas Machinery Research Council (GMRC) from a quantitative survey a number of years ago. This is the efficiency with which the compressors convert piston face HP-Hr to useful compression. The width of the range and the 12 points by which the $79 \%$ median lies below the best achieved (91\% to $92 \%$ ) represents not only gas, which is burnt rather than delivered, but also engine capacity, which must overcome losses rather than deliver useful compression of the transported gas.

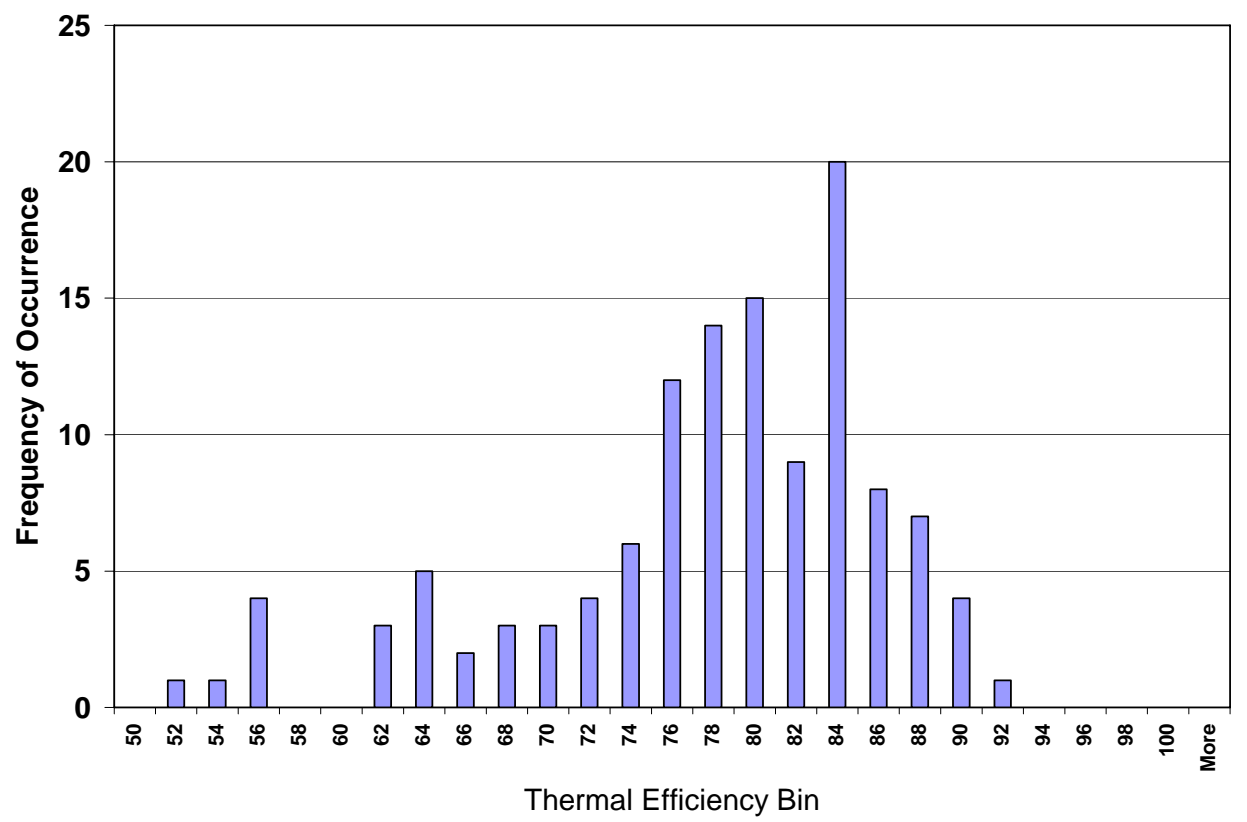

Figure 1-4. Compressor Thermal Efficiency Histogram Based on GMRC Survey

Figure 1-5 shows a number of failed crankshafts. This problem continues to occur at an undesirable rate for the pipeline industry as a whole (about one failure per thousand engines per year). This rate may not seem excessive, but for the compressor station and company, which incurs such a failure, the disruption, cost, and loss of capacity at the time is significant. The chance of this rate increasing as a penalty for improved performance and increased capacity must be avoided, as well as any increase in problems, such as bearing failure, or damage caused by detonation, or unintended overload.
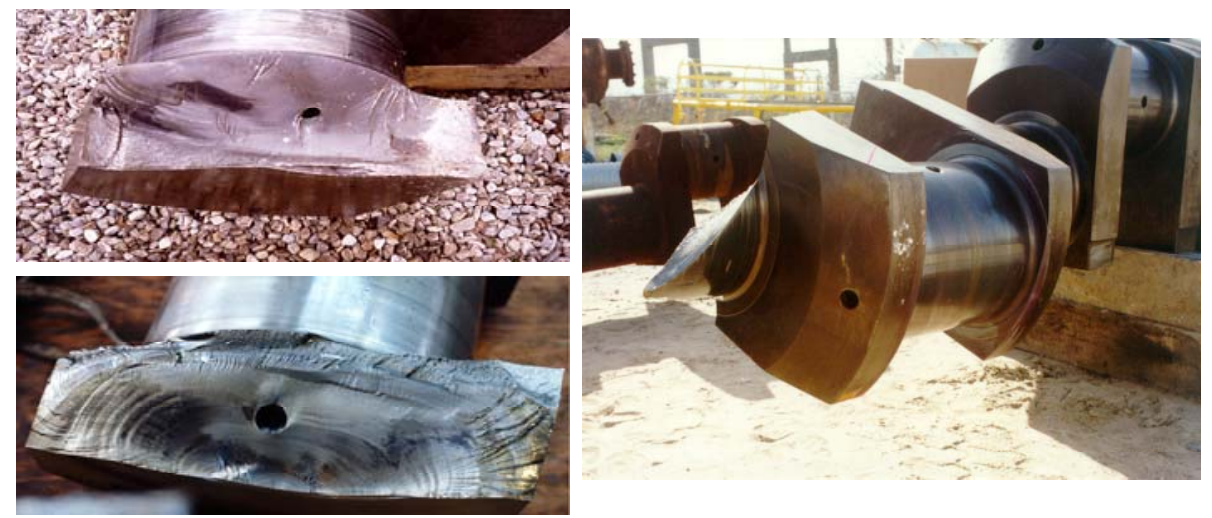

Figure 1-5. Integrity: Crankshaft Failure Examples - Need Methods of Avoidance

SwRI Project 18.06223; DOE Award No. DE-FC26-02NT41646 


\subsection{THE COMPRESSION INFRASTRUCTURE PROJECT}

Three years ago, the U.S. Department of Energy (DOE) initiated a Natural Gas Infrastructure (NGI) program whose goals included increasing capacity of the current pipeline infrastructure (10\%) and reducing operational costs (50\% by 2010). As part of this program, Southwest Research Institute ${ }^{\circledR}\left(\mathrm{SwRI}^{\circledR}\right)$ is undertaking a project entitled, "Technologies to Enhance the Operation of Existing Natural Gas Compression Infrastructure.” This project is managed for DOE by the National Energy Technology Laboratory (NETL). The project objective is:

To develop and substantiate methods for operating integral engine/compressors in gas pipeline service that reduce fuel consumption, increase capacity, and enhance mechanical integrity.

\subsection{Project Accomplishment}

This project continues to document and demonstrate the feasibility of technologies and operational choices for companies who operate the large installed fleet of integral engine compressors in pipeline service. Applying project results will enhance integrity, extend life, improve efficiency, and increase capacity, while managing $\mathrm{NO}_{\mathrm{x}}$ emissions. These benefits will translate into lower cost, more reliable gas transmission, and options for increasing deliverability from the existing infrastructure on high demand days. In the process, the project has assembled a powerful suite of instruments and a data system with which it has characterized behavior of the units tested under a wide range of conditions. This suite will remain available for characterization and optimization after completion of the project. The following documents the project's ongoing value and contribution to DOE goals.

\subsubsection{Integrity}

Increasing integrity and reducing statistical likelihood of component failure reduces transmission cost and enhances aggregate deliverability. Detonation represents a damaging threat to an engine. Applying the detonation detection technology tested under the project will mitigate this threat, which widely inhibits potentially beneficial operation with advanced timing. The newly defined CPR balancing method, which has proved quick and convenient to apply, will help equalize air/fuel ratio across cylinders and reduce the tendency to detonate. The low cost control method demonstrated for maintaining a global equivalence ratio set point provides another option for maximizing the margin between misfire and detonation limits and using commercially available controllers. The crank Strain Data Capture Module (SDCM) applied on all engines tested in the first two phases of the project has shown its value for defining conditions when crank damage rate increases. Measuring crankshaft torsional velocity has complemented the SDCM, particularly in documenting the influence of speed changes, showing also that torsional velocity data respond detectably to loss of torque from a misfire. The Rod Load Monitor evaluated and enhanced on every major test so far promises to avoid overload of engines and resulting damage by improving consistency of load torque values used in load step control. 


\subsubsection{Efficiency}

As much as 3\% of the natural gas consumed goes toward fuel gas for engines and turbines to drive compressors. This fuel gas would cost over \$3 billion at current rates-the single most significant cost of gas transportation. Increasing the aggregate efficiency with which engine/compressors convert fuel energy into useful compression work will reduce this cost and leave more of the gas in the pipeline system available to the end user. The project has already documented how high-pressure fuel injection, coupled with the addition of a turbocharger on old GMW engines, reduces heat rate by about 7\%. The demonstrated air/fuel ratio control on a rich burn, carbureted, four-stroke engine can replace manual adjustment and use of indirect measurement, allowing optimization for minimum fuel, for minimum emissions without a threeway catalyst, or for optimum catalyst performance if one is installed. The Rod Load Monitor discussed previously will allow engine operation at the point of highest efficiency (100\% torque) with greatly reduced risk of overload. The detonation detector will safely allow more efficient engine operation with timing advanced.

Comparison of the heat rate versus load characteristic has shown value as a graphical method to compare fuel conversion efficiency achieved by different engine technologies or operating decisions. This heat rate versus load comparison has revealed small potential benefits in brake thermal efficiency by applying CPR balancing. Mapping of overall system thermal efficiency has made clear the importance of considering both compressor and engine when evaluating how operational decisions will impact fuel conversion efficiency; speed/load combinations that favor heat rate may, at the same time, hurt compressor efficiency, so maximizing efficiency requires careful choices based on data. The project will continue to identify ways to enhance this efficiency, with emphasis on the compressor and pulsation control. The project has prototyped and demonstrated a methodology for use of differential indicated power (DIP) to distinguish valve and installation losses and their contribution to compressor efficiency. Results show DIP based efficiency and enthalpy based efficiency track each other quite closely. The project has also made clear the need for more information about mechanical losses and has added to this knowledge with a new interpretation of the rod load data.

Valve leaks represent a significant loss of compressor efficiency system-wide. Engine/compressor operators know the sensitivity of temperature rise to valve leaks, and the project has re-emphasized this sensitivity; the data normalization and statistical process control techniques already promoted by McKee, et al. [2], would lend themselves very effectively to monitoring of cylinder temperature rise and associated decision making based on the economic significance of valve leakage.

The project has documented air imbalance between cylinders as a widespread condition that can limit combustion efficiency. New Tasks 15 and 16 are characterizing air imbalance in more detail and are evaluating options for cost-effective solution; a side branch absorber is being built and installed and will be evaluated as an add-on modification to help reduce the contribution of fuel manifold dynamics to air imbalance.

\subsubsection{Capacity}

As discussed above, integrity enhancement and reduced component failure probability will enhance aggregate deliverability. In addition to improving the efficiency of fuel conversion, 
all increases in compressor efficiency will reduce the fraction of available engine power that must go to overcome losses and, thereby, will add to deliverability. Project tests so far have shown a compressor efficiency range from 76 to 91\%, adding to an earlier GMRC survey for a larger base of compressors with a range from 52 to 92\%! The highest compressor efficiency values found present a benchmark that will add greatly to system capacity, if more widely achieved. Current efforts under the project seek to re-emphasize compressor efficiency by characterizing and reducing compressor losses, both mechanical and thermodynamic. Measurements of flow, temperature rise, and dynamic pressure in the cylinder nozzles (as well as in the cylinders themselves) will help quantify and characterize inherent thermodynamic losses - a first step in their reduction. Previous tests have shown the likely contribution of pulsations to these losses and recent survey tests on the project have confirmed this contribution; yet, pulsation control methods, such as acoustic filters and orifices must also take account of associated resistive pressure losses.

\subsection{Field Test Program Overview}

Detailed tests and analyses have been performed so far on two different two-stroke engine models from two manufacturers and on one four-stroke engine model: a Cooper GMW10 with three compressor cylinders, a Dresser-Clark HBA-6T with four compressor cylinders, and an Ingersoll-Rand KVG103. The HBA is a straight six with a turbocharger. The GMW is a V10 and has been tested both with and without the combination of a turbocharger and highpressure fuel injection system. The KVG is a V-10 with three compressor cylinders. The engine selection was based on detailed quantitative analysis of the engine population using a database prepared for the pipeline industry, which shows all three of these tested models are in the top seven, measured by horsepower installed, and in the top six by number of units installed. Thus, marked diversity has been achieved in the process of testing three widely deployed engine models. Survey test results now also include the Dresser Clark TCVC10, part of the TCV engine family, which has the highest aggregate installed power of any engine in the pipeline system.

\subsection{CURrent Project Emphasis}

Observations from the project and from a 1990s GMRC survey (discussed previously) indicate that many low speed engine/compressor units have compressor efficiencies, which could be significantly increased. It is believed that the compressor manifold system and lateral piping between the unit and the headers contribute significantly to low compressor efficiency. On this basis, reducing installation losses (i.e., losses outside the compressor cylinder) represent an opportunity to improve compression efficiency in the U.S. pipeline system and, thereby, to increase system capacity (by reducing energy spent overcoming compressor and piping losses and making this energy available for useful compression work).

For the ongoing and final project phase, SwRI seeks to locate, characterize, and guide appropriate modifications to two slow-speed integral units whose compressor thermal efficiency suggests significant room for improvement (mid-80's or below), with a significant fraction of the losses in the installation piping (so that losses could be reduced by changes to installation or operational practice). The Industry Advisory Committee (IAC) for the project has helped SwRI to identify and characterize two candidate units, and survey site tests have now been performed on an HBA-6 at Duke Energy's Bedford Station and on a TCVC10 at Dominion's Groveport 
Station. Each unit tested demonstrates significant room for improvement in overall compression efficiency. Guided by the results, design analysis is planned for both units to quantify the benefits, which can be achieved by changes in the installed piping outside the compressor. The design analysis has already been performed for the HBA-6, with engineering data and review of options provided by the host company. The host is now implementing the planned changes. Further tests will then be performed to quantify improvements resulting from the changes. The design analysis for the TCVC10 is also planned for the near future. After summarizing test results from both sites, this report presents the design analysis for the HBA-6 and the options selected for implementation. 


\section{EXPERIMENTAL}

\subsection{OVERVIEW}

The majority of this section describes the suite of instruments, which have been used in tests so far for intensive testing of the power and compression sides of integral engine compressors. This description is included in this report for completeness and for reference. Two survey tests have also provided data to guide design analysis, installation changes, and further testing with emphasis on efficiency and capacity of the compressor, its compressor manifold system, and its attached piping.

In the following list of sensors and data channels (Section 2.2), which comprises the full suite used in field tests so far, a pair of asterisks and specific discussion denote those from the full list which make up the much reduced set of sensors and data channels used for the "survey tests".

An additional section (2.3) briefly summarizes changes in the instrumentation suite, which are under discussion for use in further testing to emphasize compressor side performance.

\subsection{Sensors and Data Channels for Field Measurement}

Sensors and data acquisition capabilities have been assembled to record the following data on large integral engine compressors.

- $\quad$ **Dynamic Pressure in the Compressor Cylinders - These measurements are used for compressor horsepower and flow determination. Both ends of each compressor cylinder have been instrumented for dynamic pressure in each test series. The sensors are Sensotec piezo-restrictive transducers. They are calibrated prior to each test by deadweight loading to generate known force per unit area in the test fluid applied to the sensing element.

For the survey site tests discussed in this report, "roving” pressure transducers are used. Rather than install, calibrate, checkout, and concurrently acquire data from a transducer on every end of every cylinder, data is acquired from one cylinder at a time, and then the set of transducers is removed from that cylinder and re-installed on the next cylinder to be tested. The benefit is a much faster set-up for a screening test; as a penalty for this benefit, the survey site data does not provide concurrency and longer term concurrent trending. Recent enhancement employs a heater on each sensor, which keeps the sensor at a uniform temperature and helps reduce the uncertainty caused by calibration drift resulting from temperature variation. As discussed below, these heated sensors are also being applied on the suction and discharge nozzles and suction and discharge lateral lines ("laterals").

- $\quad$ Dynamic Pressure in the Engine Cylinders - These measurements are used for engine horsepower determination, engine balancing, and to calculate engine statistics. All power cylinders have been instrumented for dynamic pressure in each test series. The sensors are Kistler quartz piezoelectric transducers. Because they are dynamic sensors, they are calibrated prior to each test by suddenly applied 
deadweight loading to generate known force per unit area in the test fluid applied to the sensing element.

- $\quad$ Dynamic Pressure in the Engine Air Intake Manifold - These measurements are used to correlate dynamic effects in the inlet manifolds, which deliver air for each cylinder with the dynamic statistics within each cylinder. They also provide the time-averaged value for air manifold pressure whose influence on engine heat rate and emissions is assessed. Air manifolds have been instrumented in each test series. The sensors are Kistler piezo-resistive pressure transducers with factory provided calibration.

- $\quad$ Dynamic Pressure in the Engine Exhaust Manifold - These measurements are used to determine dynamic variation of pressure in the engine manifolds, which capture hot exhaust gas from each cylinder, and to correlate these dynamic pressure variations with the dynamics within each cylinder. The sensors are Kistler piezoresistive transducers with factory provided calibration; they are water-cooled to reduce uncertainty resulting from temperature influence on the sensor readings. It has not been possible to install these transducers on exhaust manifolds with water jackets.

- Torsional Vibrations (IRV) - This measures the dynamic variation in speed of rotation of the flywheel. The sensor is a BEI 512 pulse encoder driven through a flexible coupling by a shaft connected by a friction drive to the flywheel. The frequency of its output pulse train directly reflects instantaneous flywheel angular velocity, which varies within each cycle of the engine because of dynamic load variation. Rather than digitally time the variation in the period between pulses (which imposes unrealistic period discrimination requirements), a frequency to voltage analog circuit is used to determine the continuous variation in flywheel speed. The frequency-to-voltage measurement is calibrated by supplying the analog circuitry with a pulse train of known frequency from a signal generator. The torsional vibration has been measured in this way on all tests. The torsional vibration data have been assessed as a potential indicator of engine dynamic loading severity.

- $\quad$ **Data Acquisition Triggering - The BEI encoder signal is also used to trigger acquisition of samples from all dynamic transducers. The phasing of the pulse train to top dead center (TDC) is important. A pre-established top dead center mark for power Cylinder 1 is used as a reference, and the angular setting within the DAS corresponding to Cylinder 1 TDC is adjusted, as the engine runs, until a strobe light triggered by the DAS at this angle shows that the mark on the flywheel coincides with the stationary mark.

The same encoder and triggering methodology are used for the survey site tests in conjunction with the transducer set installed on each cylinder in turn.

- $\quad$ Bearing Centerline Vibration - This measurement is assessed as an indicator of engine dynamic loading severity. The sensors are PCB velocimeters with factory provided calibration. The sensors have been located to measure lateral vibration at each end of the engine/compressor frame. 
- $\quad$ Crankshaft Dynamic Strain - This measurement is used as a direct indicator of shaft loading and to provide a link between engine statistical quantities and potential for crankshaft fatigue damage (Harris, et al., [3]). The strain gage is placed on the crankshaft web as close as possible to the crank pin-at the point most sensitive to opening and closing of the crank throw faces under load from engine and compressor rods. Data are acquired by the Strain Data Capture Module (SDCM), which rides on the shaft within the engine during each day of testing and from which data are downloaded at the end of each day. This is calibrated using a calibration resistance. The SDCM has worked with complete reliability for all tests so far. Its main drawback is the need for daily download, which can cut into test time; a refinement is under consideration that increases storage and energy capacity by a factor of ten or more.

- $\quad$ Engine Fuel Flow used to document overall engine efficiency - This sensor is an Emerson Flobas 103 transmitter that implements the AGA3 flow measurement based on a differential pressure measurement and is factory calibrated with a certificate. It is connected to taps on the already installed engine fuel flow orifice, which has been available on all engines tested so far. The fuel flow, coupled with a gas analysis, provides the basis for determining fuel energy consumed by the engine and for determining heat rate and overall system efficiency. At the first test, the flow measurement functioned, but the flow range was not properly matched to the engine, and satisfactory data was not obtained. At subsequent tests, the fuel flow has been successfully measured and used for the intended purposes.

- $\quad$ **Pressures and Temperatures in Headers and Laterals (Suction, Discharge) These measurements are used for installation efficiency determination. Pressures are measured with Sensotec piezo-restrictive transducers. Permanently installed station sensors have also been used to provide these data at some sites.

For the survey site tests (and for several of the full scale tests undertaken), pressure and temperature data in the suction and discharge headers has also been obtained from permanently installed station instruments. The standard station instruments are transmitters without dynamic pressure response capability, but when well calibrated, they provide accurate data on the operating conditions for the tested unit.

To supplement cylinder pressure and station header pressure data, the survey site test reported herein has also used dynamic pressure measurement in the unit laterals and in the suction and discharge nozzles. This enables interaction of pressures at these locations and of cylinder power to be evaluated. The heated sensors used for this purpose have been discussed above and will be illustrated in the results and discussion section (Section 4) of this report.

- Engine Exhaust $\mathrm{O}_{2}$ Level - This measurement is used to determine global equivalence ratio, both as an independent variable influencing engine performance, and where the loop is closed to the turbocharger waste gate (two-stroke) or fuel rate valve (four-stroke) for active control. The sensor used is an NGK fast-response transducer, which provides a continuous variation of voltage with exhaust oxygen level. It is calibrated against a standard. 
- $\quad$ Engine Exhaust $\mathrm{NO}_{x}$ Level - This measurement is used to provide comparative emissions data. The sensor used is an NGK fast-response transducer that provides a continuous variation of voltage with exhaust $\mathrm{NO}_{\mathrm{x}}$ level. It is calibrated against a standard.

- $\quad$ Compressor Rod Load - This measurement is used for both mechanical integrity and loading optimization. The sensor uses a pair of strain gages mounted on either side of the rod, which are bridged additively to cancel bending and to produce a signal proportional to axial load on the piston rod. The signal is transmitted using RF from a moving antenna to a stationary antenna. The strain gage and signal transmission can be powered by a battery or by a generator driven by rod motion. The battery power is adequate and simpler to set up for short-term tests, but for continuous monitoring and control, self-powering is needed. Calibration issues are not fully resolved yet for this device [termed the "Rod Load Monitor" (RLM)]. So far, the horsepower measurement from the compressor cylinder, based on cylinder pressure transducer, has been used for calibration.

- $\quad$ Knock Detection - This sensor, provided as a loan to the project by Metrix, counts occurrences of dynamic acceleration levels above a threshold, to detect detonation.

\subsection{Potential Instrument Changes for Compressor Side Testing}

The following potential changes to the instrument suite make-up are under consideration for the remaining intensive testing in which it is planned to emphasize compressor side performance.

- $\quad$ Nozzle Dynamic Pressure Measurement - This has been discussed above in relation to the survey site tests. Knowledge of dynamic pressure variation in the nozzles acquired coherently with dynamic pressure variation in cylinder, laterals, and headers allows for more specific assessment of the time integrated pressure drop across the compressor valves between cylinder and nozzles, and also provides a reference for assessing pressure drop through compressor manifold and lateral piping between nozzles and headers. Effective interpretation of these pressures demands accurate and consistent calibration for all the pressure transducers involved.

- Compressor Natural Gas Flow Measurement - This is a very challenging measurement because of flow modulations and local noise, particularly if dynamic variation of flow over a compressor cycle is to be distinguished. If it can be accomplished, the knowledge will help define the influence of operational parameters on compressor capacity and will better define the power loss (flow weighted pressure drop) across sections of system piping.

- Compressor Suction and Discharge Temperature Measurement - This measurement is within the existing state of the art. A well-calibrated temperature measurement, coupled with reliable and co-located pressure measurement, with the knowledge of compressed gas composition and accurate thermo-physical properties for the operating conditions, enables deviations from isentropic compression to be 
accurately assessed, and the influence of operational and configurational changes on these deviations to be evaluated.

- $\quad$ Basis for Compressor Mechanical Loss Assessment - The Rod Load Monitor evaluated at each detailed test undertaken so far has shown its potential for distinguishing the mechanical friction losses incurred by the compressor piston rings and rider bands. While piston friction is not readily amenable to design changes, the knowledge of how operation affects piston friction losses can become significant when operational changes are under consideration for other purposes.

\subsection{LABORATORY GMVH MEASUREMENTS FOR AIR BALANCE TASKS}

The GMVH engine was highly instrumented prior to utilization for the air balance investigation. However, additional dynamic pressure measurements were required for proper simulation with the computational model. The additional instrumentation is as follows:

- Dynamic Pressure in Exhaust Manifold Runners - Prior to the air balance investigation, only Cylinder 1L was instrumented for dynamic exhaust pressure. Additional dynamic pressure sensors were added to the remaining five cylinders to capture the dynamic pressure pulsations of the exhaust from each cylinder's ports. These sensors are of a thin-film strain gage type, typically used for absolute pressure measurement of manifold pressure in automotive electronic engine control systems. Each sensor was calibrated and a comparison test to a Kistler piezoresistive sensor was performed on the running engine to validate transient response.

- $\quad$ Dynamic Pressure in Exhaust Manifold Plenum - A new sensor was installed in the exhaust manifold plenum near the turbocharger. This measurement is required to capture the dynamic pressure pulsations in the exhaust manifold plenum and provide data to characterize the dynamic flow through the exhaust manifold. A Kistler piezo-resistive absolute pressure transducer was utilized for this measurement. This sensor was calibrated via a deadweight tester. A photograph of the exhaust plenum sensor as installed for testing is provided in Figure 2-1.

- Dynamic Pressure in Inlet Manifold Plenums - Prior to the air balance investigation, only the left inlet manifold was instrumented for dynamic inlet plenum pressure. An additional dynamic pressure sensor was added to the right inlet manifold plenum to capture the dynamic pressure pulsations of the exhaust from each cylinder's ports. These sensors are of a thin-film strain gage type, like those utilized in the exhaust manifold runners.

The complete instrumentation package on the laboratory GMVH engine is listed in Table 2-1. 


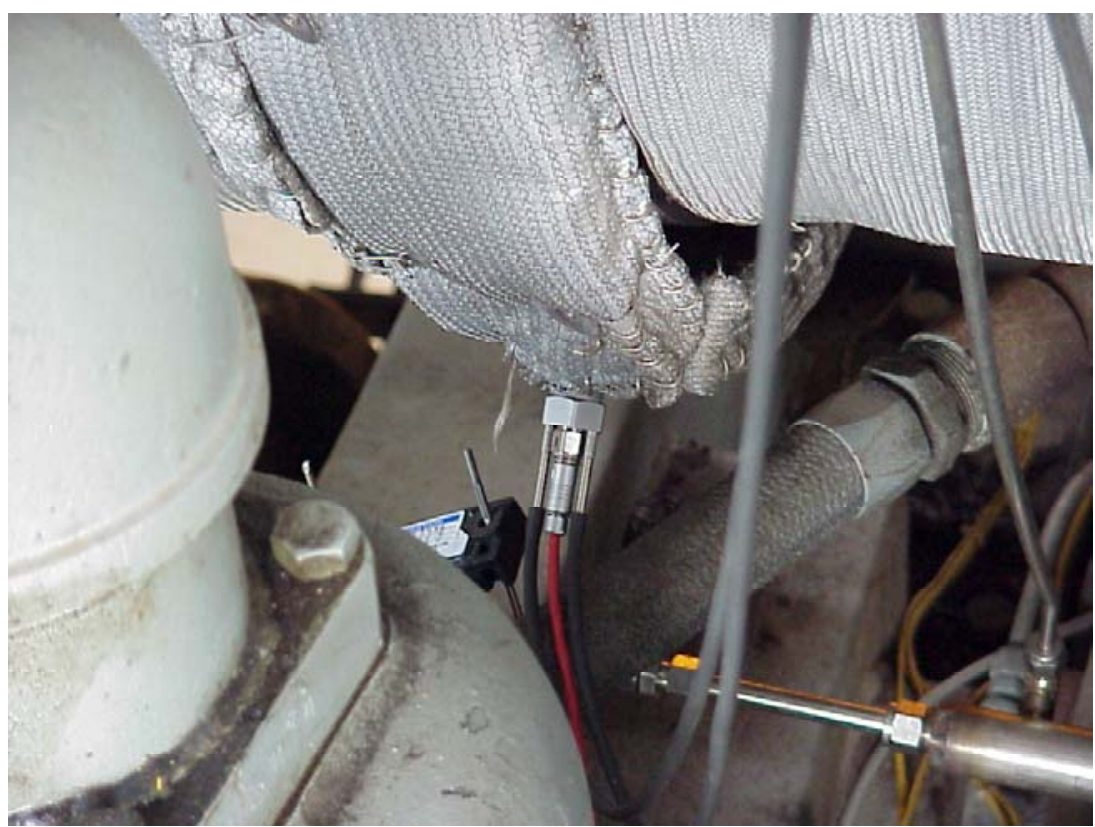

Figure 2-1. Photograph of Dynamic Exhaust Pressure Sensor in Exhaust Plenum

Table 2-1. Time-Averaged and Crank-Angle Resolved Measurements on GMVH

\begin{tabular}{|l|l|}
\hline Time-Averaged Measurements & Oil Pressure \\
\hline Engine Speed & Turbocharger Oil Pressure \\
\hline Turbocharger Shaft Speed & Coolant Inlet \& Outlet Pressure \\
\hline Turbocharger Wastegate Position & Pre-Turbine Pressure \\
\hline Engine Torque & Stack Pressure \\
\hline Total Fuel Flow & Compressor Inlet Temperature \\
\hline Pre-Chamber Fuel Flow & Compressor Left \& Right Outlet Temperatures \\
\hline Fuel Gas Composition & Inlet Manifold Left \& Right Temperatures \\
\hline Fuel Gas Heating Value & Fuel Header Temperature \\
\hline Total Air Flow & Pre-Chamber Header Temperature \\
\hline Barometric Pressure & Individual Cyl. Exhaust Runner Temperatures \\
\hline Ambient Temperature & Pre-Turbine Temperature \\
\hline Ambient Humidity & Post-Turbine Temperature \\
\hline Exhaust NOx Concentration & I/C Inlet Left \& Right Water Temperatures \\
\hline Exhaust CO Concentration & I/C Outlet Left \& Right Water Temperatures \\
\hline Exhaust HC Concentration & Oil Sump Temperature \\
\hline Exhaust CO2 Concentration & Oil Inlet Temperature \\
\hline Exhaust O2 Concentration & Turbocharger Oil Inlet Temperature \\
\hline Exhaust Equivalence Ratio & Coolant Inlet \& Outlet Temperatures \\
\hline Inlet Manifold Left \& Right Pressures & Individual Cyl. Head Temperatures \\
\hline Fuel Header Pressure & Dynomometer Inlet \& Outlet Temperatures \\
\hline Pre-Chamber Header Pressure & Cylinder 1L Exhaust Runner Pressure \\
\hline Crank-Angle Resolved (Dynamic) Measurements \\
\hline Cylinder 1L Firing Pressure & Cylinder 2L Exhaust Runner Pressure \\
\hline Cylinder 2L Firing Pressure & Cylinder 3L Exhaust Runner Pressure \\
\hline Cylinder 3L Firing Pressure & Cylinder 1R Exhaust Runner Pressure \\
\hline Cylinder 1R Firing Pressure & Cylinder 2R Exhaust Runner Pressure \\
\hline Cylinder 2R Firing Pressure & Cylinder 3R Exhaust Runner Pressure \\
\hline Cylinder 3R Firing Pressure & Right Inlet Manifold Plenum Pressure \\
\hline Left Inlet Manifold Plenum Pressure & Exhaust Manifold Plenum Pressure \\
\hline Cylinder 1L Pre-Chamber Firing Pressure & \\
\hline
\end{tabular}


In addition to the many measurements for engine performance and emissions, several static measurements were made of the engine geometry. These geometric measurements have been determined to be of critical importance for proper simulation of the engine. The key geometric parameters to be determined are compression ratio, port timing, and port area in each cylinder of the test engine. In order to conduct the many detailed measurements, the engine was disassembled. A list of the many static measurements taken on each cylinder is provided in Table 2-2. From these measurements, several calculated parameters were derived and discussed in the next section.

Table 2-2. Static Measurements on Each Cylinder of GMVH

\begin{tabular}{|c|c|}
\hline Piston Stroke (BDC to TDC) & Cylinder Bore ( 1" from top) \\
\hline Connecting Rod C-C (cyl 1L only) & Piston TDC Height (from cylinder top) \\
\hline Pre-Chamber Volume & Piston Top Ring Land Diameter \\
\hline Cylinder Inlet Volume (inc.ports) & Piston Top Ring Land Height \\
\hline Cylinder Intake Flange Width & Piston Dome Angle \\
\hline Cylinder Intake Flange Height & Piston Dome Height from edge \\
\hline Cylinder Exhaust Flange Width & Piston Bowl Depth \\
\hline Cylinder Exhaust Flange Height & Piston Bowl Volume (inc puller-hole) \\
\hline Cylinder Head Volume & Piston Pin Center to Crown Height \\
\hline Cylinder Head Gasket Step & Top Int Port to Gasket Step - A \\
\hline Cylinder Head Gasket Thickness & Top Int Port to Gasket Step - B \\
\hline Exhaust Port "Shape" - A & Top Int Port to Gasket Step - C \\
\hline Exhaust Port "Shape" - B & Top Int Port to Gasket Step - D \\
\hline Exhaust Port "Shape" - C & Top Int Port to Gasket Step - E \\
\hline Exhaust Port "Shape" - D & Top Int Port to Gasket Step - F \\
\hline Exhaust Port "Shape" - E & Top Int Port to Gasket Step - G \\
\hline Top Exh Port to Gasket Step - A & Top Int Port to Gasket Step - H \\
\hline Top Exh Port to Gasket Step - B & Intake Port to Edge Width - A \\
\hline Top Exh Port to Gasket Step - C & Intake Port to Edge Width - B \\
\hline Top Exh Port to Gasket Step - D & Intake Port to Edge Width - C \\
\hline Top Exh Port to Gasket Step - E & Intake Port to Edge Width - D \\
\hline Exhaust Port Edge Width - A & Intake Port to Edge Width - E \\
\hline Exhaust Port Edge Width - B & Intake Port to Edge Width - F \\
\hline Exhaust Port Edge Width - C & Intake Port to Edge Width - G \\
\hline Exhaust Port Edge Width - D & Intake Port to Edge Width - H \\
\hline Exhaust Port Edge Width - E & Intake Port Edge Height - A \\
\hline Exhaust Port Min Width - A & Intake Port Edge Height - B \\
\hline Exhaust Port Min Width - B & Intake Port Edge Height - C \\
\hline Exhaust Port Min Width - C & Intake Port Edge Height - D \\
\hline Exhaust Port Min Width - D & Intake Port Edge Height - E \\
\hline Exhaust Port Min Width - E & Intake Port Edge Height - F \\
\hline Exhaust Port Edge Height - A & Intake Port Edge Height - G \\
\hline Exhaust Port Edge Height - B & Intake Port Edge Height - H \\
\hline Exhaust Port Edge Height - C & Intake Port Angle - A \\
\hline Exhaust Port Edge Height - D & Intake Port Angle - B \\
\hline Exhaust Port Edge Height - E & Intake Port Angle - C \\
\hline Exhaust Port Min Height - A & Intake Port Angle - D \\
\hline Exhaust Port Min Height - B & Intake Port Angle - E \\
\hline Exhaust Port Min Height - C & Intake Port Angle - F \\
\hline Exhaust Port Min Height - D & Intake Port Angle - G \\
\hline Exhaust Port Min Height - E & Intake Port Angle - H \\
\hline
\end{tabular}


Two of the six cylinders, representing a high and low compression pressure on a given bank, were to be flow tested. During disassembly, it was found that Cylinder $1 \mathrm{R}$ had a different exhaust port shape from the other cylinders and was removed to be flow tested. Therefore, Cylinders $1 \mathrm{~L}, 3 \mathrm{~L}$, and $1 \mathrm{R}$ were removed from the engine. The flow testing was conducted to measure the discharge coefficient of both intake and exhaust ports versus open area. Accurate discharge coefficients are required for accurate simulation. In addition, a review of allowable port shape on the manufacturing drawings gave concern that variance in port shape from cylinder-to-cylinder could be a large contributor to flow imbalance. The effects of port shape also needed to be characterized and accounted for in the simulations.

A flow test rig was assembled specifically for this effort. This test rig featured a compressed air storage and regulation system, meter run, data acquisition, and cylinder stand. Photographs of the flow bench rig are shown together in Figure 2-2. The compressed air system featured three 1,050-gallon cylinders charged to 250 PSIG. The outlet of the compressed air cylinders was connected to a regulator and control valve for setting the desired pressure versus mass flow of air into the flow bench. The meter run was fabricated from Schedule 40 PVC pipe and featured an ASME nozzle for flow measurement. Two sizes of flow nozzles, 2- and 4-inch, were interchangeably used for low and high flows. Mass flow was calculated from the volumetric flow measurements using standard equations given in ASME codes. The cylinder stand was fabricated to hold and seal the cylinder during testing. An adjusting screw protruded from the bottom of the stand to allow for adjustment of piston height to achieve the desired port open fraction. A Vernier scale mounted on the bottom of the stand was used for measuring piston travel. A fixture was later fabricated to mount on the cylinder studs to lock the piston and prevent lifting due to air pressure leaking past the rings and under the piston. The data acquisition system acquired data at a rate of $6 \mathrm{~Hz}$ and included the measurements given in Table 2-3.

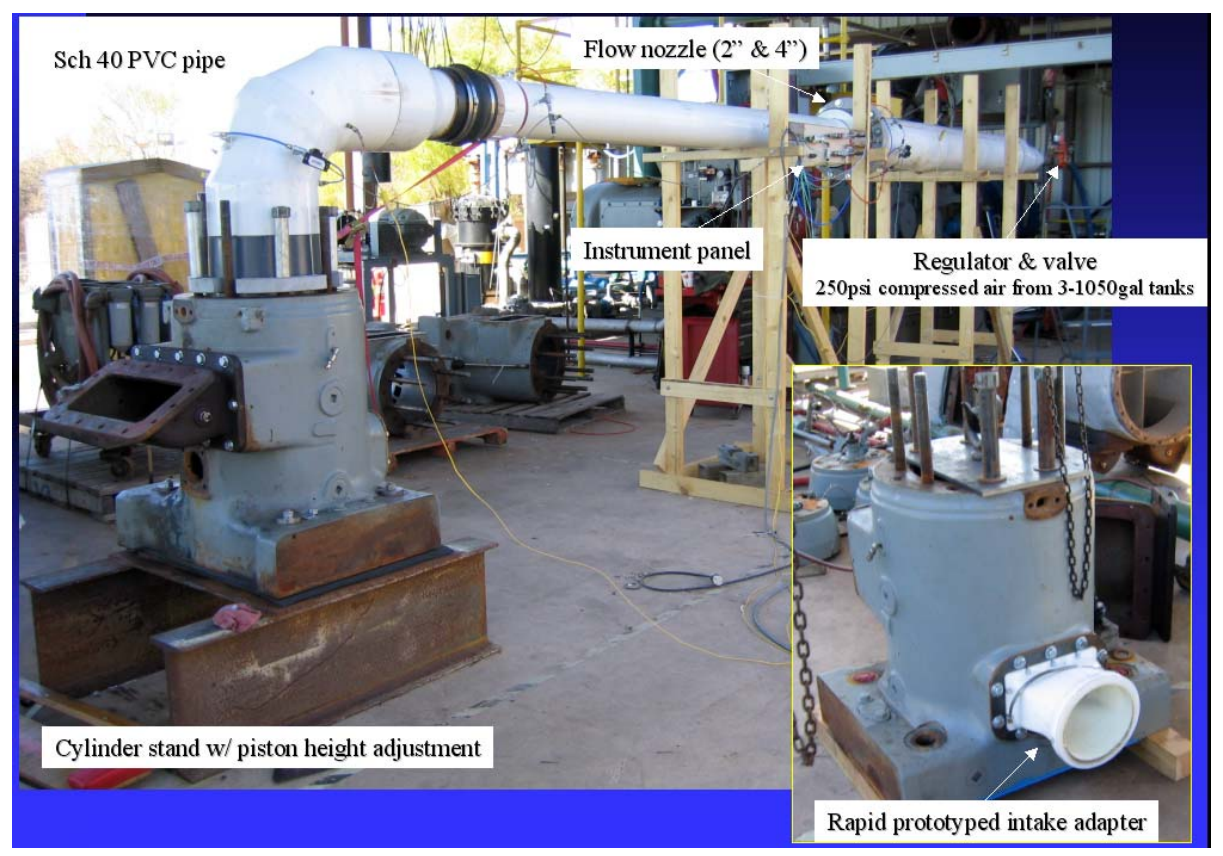

Figure 2-2. Photographs of GMVH Cylinder Flow Bench 
Table 2-3. GMVH Cylinder Flow Bench Measurements

\begin{tabular}{|l|l|}
\hline Supply Static Pressure (upstream) & Ambient Pressure \\
\hline Supply Temperature (upstream) & Ambient Temperature \\
\hline 4" Nozzle delta-Pressure & Ambient Dewpoint Temperature \\
\hline 2" Nozzle delta-Pressure & Air Tank Pressure \\
\hline Plenum Static Pressure (downstream) & Piston Travel from BDC \\
\hline Plenum Temperature (downstream) & \\
\hline
\end{tabular}

Results from recent simulations with the additional measurements incorporated have shown that the actual inlet air temperature, passing through the ports, is significantly hotter than that measured in the inlet manifold. This increased inlet air temperature is due to a portion of the air mass coming from the large plenum in the base, where the air is heated closer to oil temperature. Additional temperature sensors have been installed directly into the air box of two cylinders to validate the model predictions of elevated inlet air temperature.

\subsection{Computational Modeling for Air Balance InVEstigation}

The computational modeling for the air balance investigation is being performed with software purchased from Optimum Power Technology. The particular software package is titled Automated Design with Virtual 2-Stroke. This software is a one-dimensional cycle-simulation model that focuses on the fluid dynamics in an internal combustion engine.

A model of the GMVH engine was configured using the dimensions provided by Cooper Compression and obtained through direct measurement. Being a one-dimensional computational model, many of the complex three-dimensional geometries were simplified to representative pipes, plenums, junctions, and orifices. A schematic of the current computational model of the GMVH-6 engine is provided in Figure 2-3. This model now incorporates the base plenum and more precise geometric dimensions derived during engine teardown.

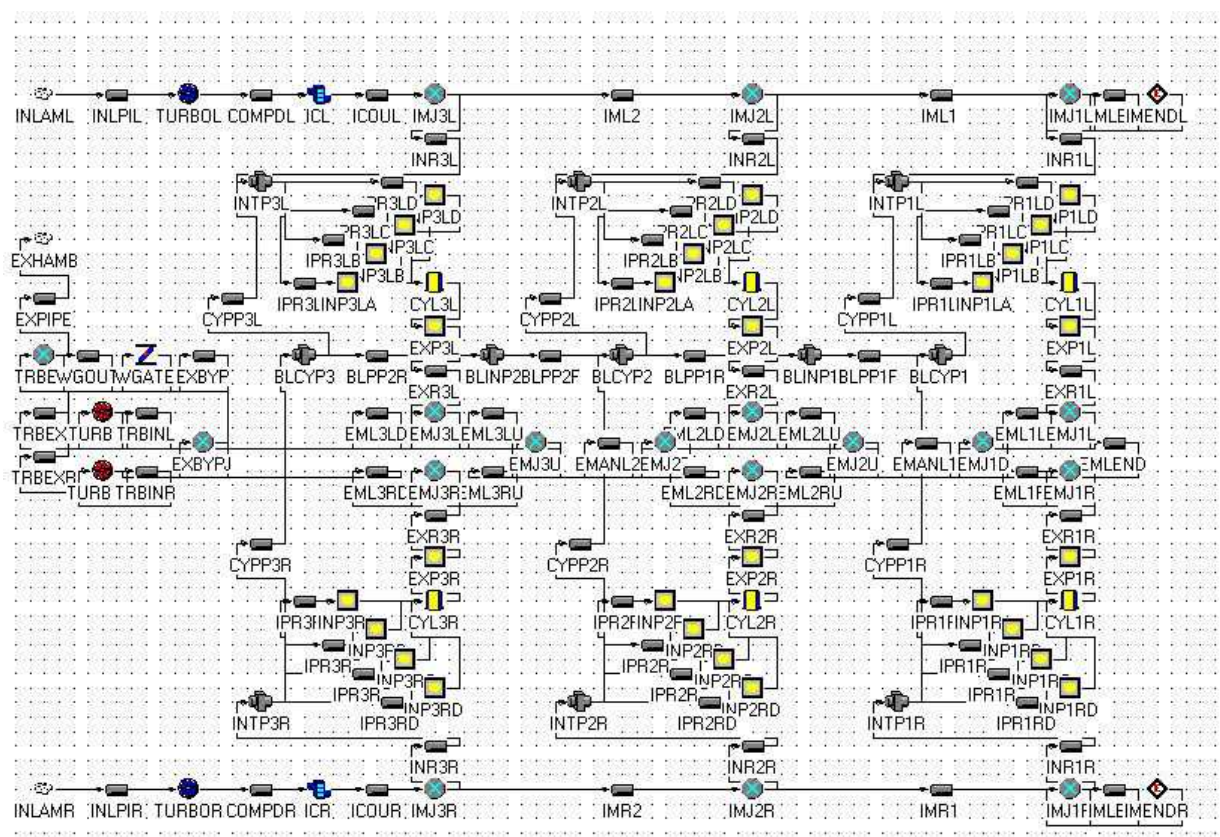

Figure 2-3. Current GMVH Computational Model Schematic

SwRI Project 18.06223; DOE Award No. DE-FC26-02NT41646 


\section{DATA ACQUISITION}

\subsection{FieLd DATA SyStem}

Figure 3-1 and Figure 3-2 show photographs of the Field Data Acquisition System (DAS). The system comprises an industrially hardened computer, a flat screen for display, and a separate box with connectors to which cables from individual sensors are connected. The DAS box has analog-to-digital converters of appropriate speed for over 50 different channels.

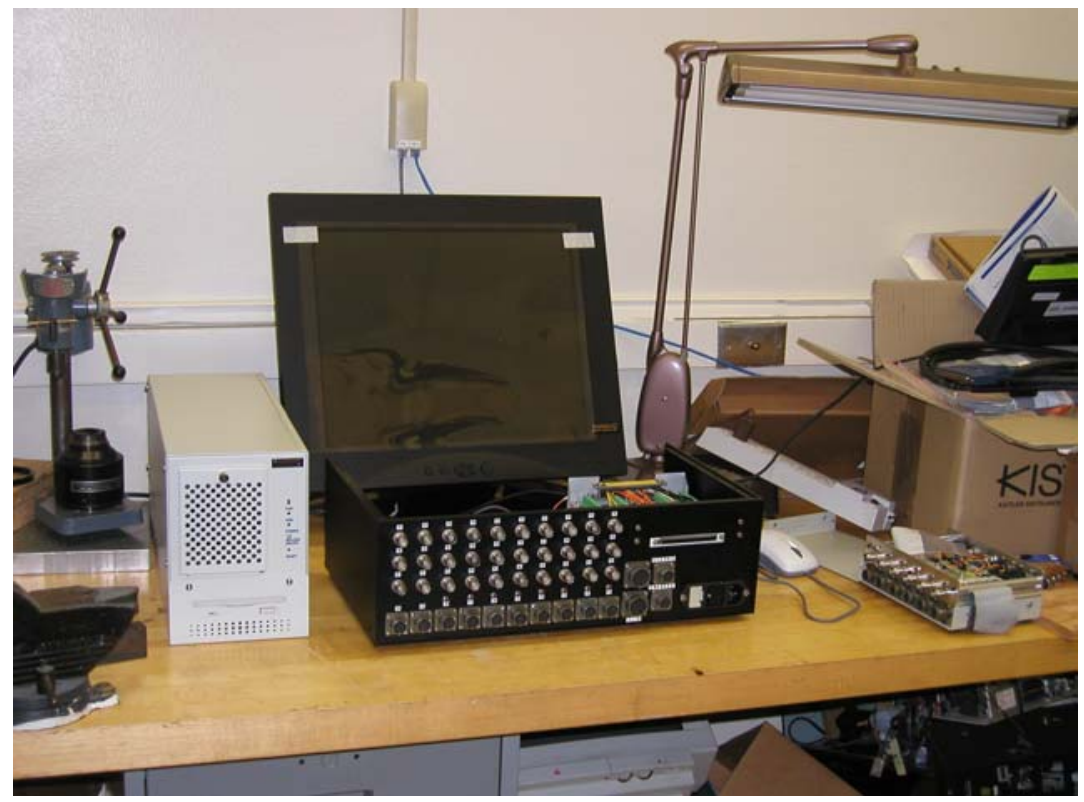

Figure 3-1. Front View of Field Data Acquisition System (DAS)

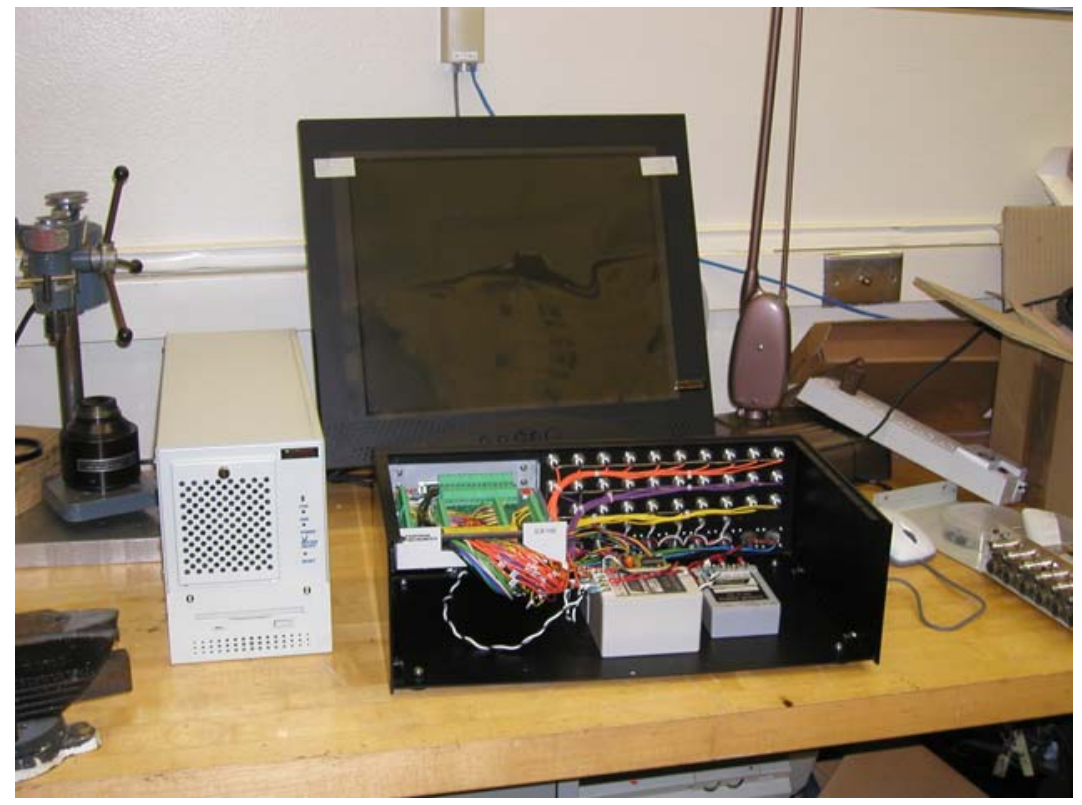

Figure 3-2. Rear View of Field Data Acquisition System (DAS) 
The individual power cylinder transducers (up to 10) are connected to a box with connectors on the deck near the cylinders. A single cable from this box carries the signals from all the power cylinder transducers to the main data acquisition box. A similar approach is used for the compressor cylinders. In this way, the complexity of the cabling and system checkout is minimized. Signals from rod load monitors from other system pressures and from temperature sensors are acquired by the DAS, concurrently, and a database of the sensor values throughout each test is created by the DAS.

\subsection{Data Acquisition for Survey Site Tests}

A PC-based data acquisition system is being used for the survey site tests. This system does not have the extensive channel capacity of the data acquisition system used in detailed testing at sites documented in previous reports. However, it is adequate for the reduced number of channels required for concurrent data acquisition on cylinder head- and crank-end, suction nozzle, discharge nozzle, and suction and discharge laterals (i.e., 6 channels). A transducer "break-out" box is used, which conditions the signal from the pressure transducers, together with an analog to digital (A to D) converter between the break-out box and the computer. Sampling by the A to D card is triggered by pulses from the encoder, which is driven by a quill shaft connected to the crankshaft at the flywheel.

The processing software is identical to that used by the higher capacity system in previous tests. Normally, this software is designed to acquire data at 512 angular subdivisions of 360 degrees of rotation, over 32 successive revolutions of the crankshaft, and to average the 32 values obtained at each of the 512 rotation angles. This averaging or "comb-filtering" process tends to minimize or eliminate random cycle-to-cycle variations and to reinforce persistent characteristics of the pressure variations.

During the first survey site test, the need was identified to characterize systematic variation in the pressure data, which was occurring at a slow frequency (fractions of a Hz). The averaging process, which normally aids the data acquisition process, was found to work against the need for this characterization, and a field modification was made to allow the capture and storage and analysis of individual pressure records, yielding information on how instantaneous power and pulsations were varying.

\subsection{LABORATORY GMVH ENGINE}

A photograph of the laboratory GMVH instrumentation and control panel is depicted in Figure 3-3. The data acquisition system is PC-based, and features custom software written by SwRI. In addition to recording and displaying the measurements listed in Section 2.4, the data acquisition software is programmed with many calculated parameters that are displayed in realtime for monitoring performance and setting specific operating conditions. 


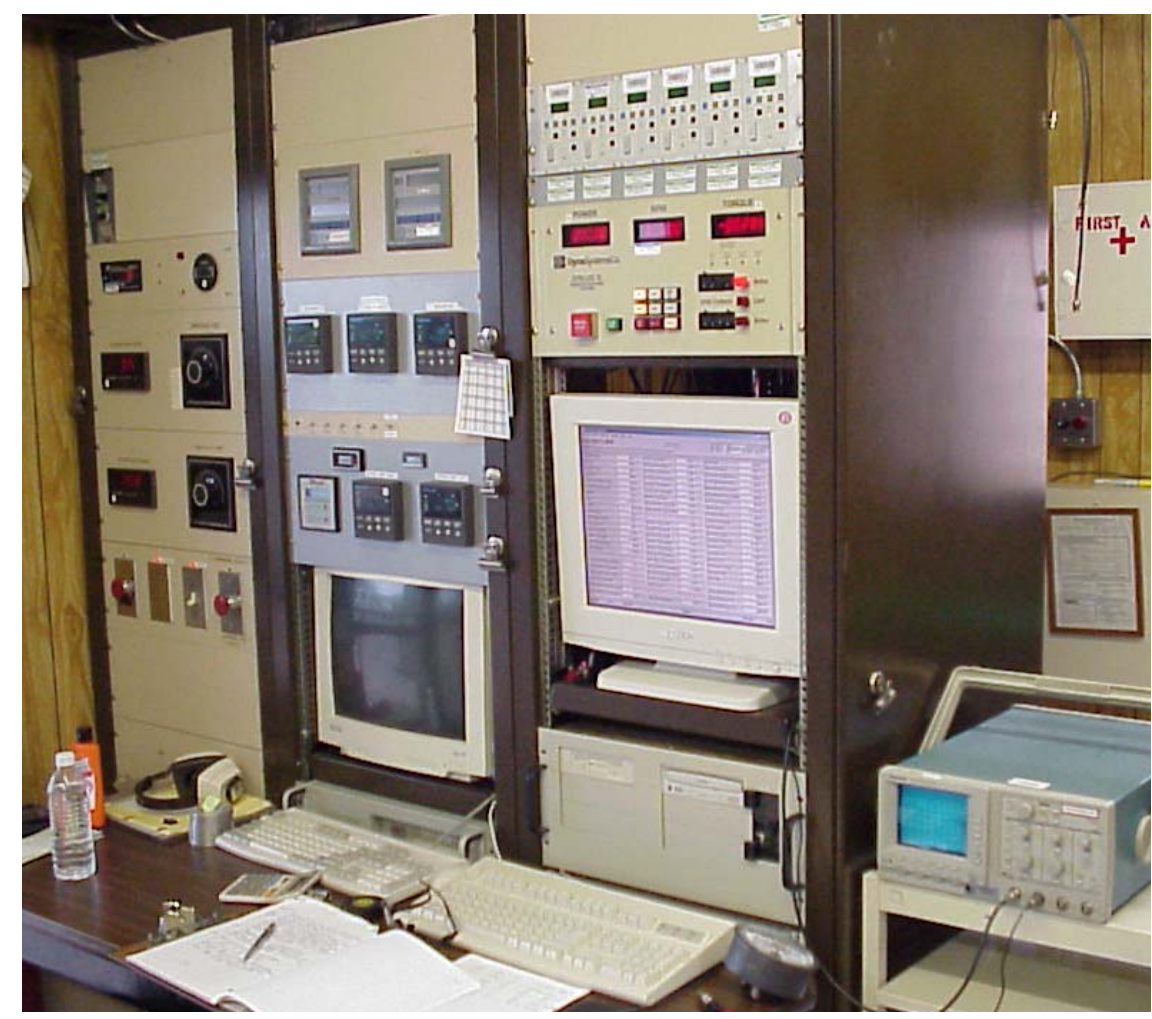

Figure 3-3. Laboratory GMVH Instrumentation and Control Panel 


\section{RESULTS AND DISCUSSION: SITE TEST SUMMARY AND HBA-6 DESIGN ANALYSIS}

\subsection{OVERVIEW AND BACKground to SURVEY TeStS}

The site for the first survey test was Duke Energy's Bedford Station, with nine HBA-6 units. Figure 4-1 shows the HBA-6 unit tested March 1, 2005. Nominal power and speed for this engine are 1,320 $\mathrm{HP}$ and $300 \mathrm{RPM}$. Power cylinder bore is 17 inches and stroke is 17 inches. Since the original installation of these reciprocating compressors, two centrifugal compressors have been added at the station with electric motor drives. Operating conditions at the station have changed, with an increase in nominal discharge pressure from 800 PSIG to 1,000 PSIG. To accommodate this change without overloading the individual reciprocating compressor units, the capability to deactivate one end on one or more compressor cylinders has been added. The screening tests documented significant pulsations under single-acting conditions. The results further showed that the single-acting pulsations varied over time with a period of several seconds, leading to time-varying compressor cylinder performance. Doubleacting operation was steadier; it exhibited lower pulsations and showed a thermal efficiency, which was about three percentage points higher than under single-acting conditions.

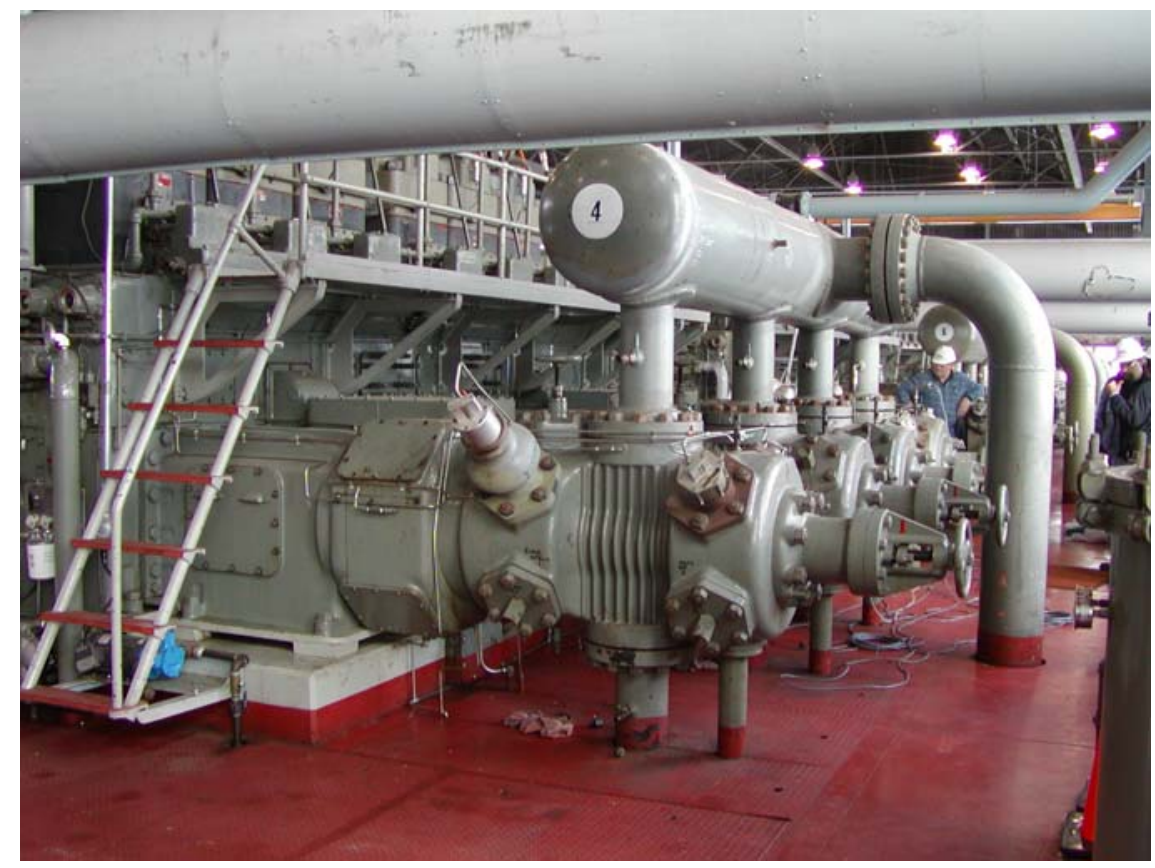

Figure 4-1. Overview Photograph of HBA-6 Unit (Duke Energy's Bedford Station; March 1, 2005)

The site for the second survey test was Dominion's Groveport Station, which operates three TCVC10 integral engine compressors. The TCV model is the top engine in the U.S. natural gas pipeline system when measured by installed horsepower (872,000 HP in the 1998 Coerr Database) and the eighth engine when measured by number of units installed (155 Units). Figure 4-2 shows the TCVC10 unit tested April 20, 2005. The turbocharged Vee engine has a nominal power of 5,000 HP, with a power cylinder bore of 18.5 inches and a stroke of 19 inches; 
it runs at a nominal speed of 330 RPM. The Groveport Station operates in either transmission or storage mode and runs with as high a service factor as can be achieved. Poor performance and high vibration have been observed on the units at Groveport since installation.

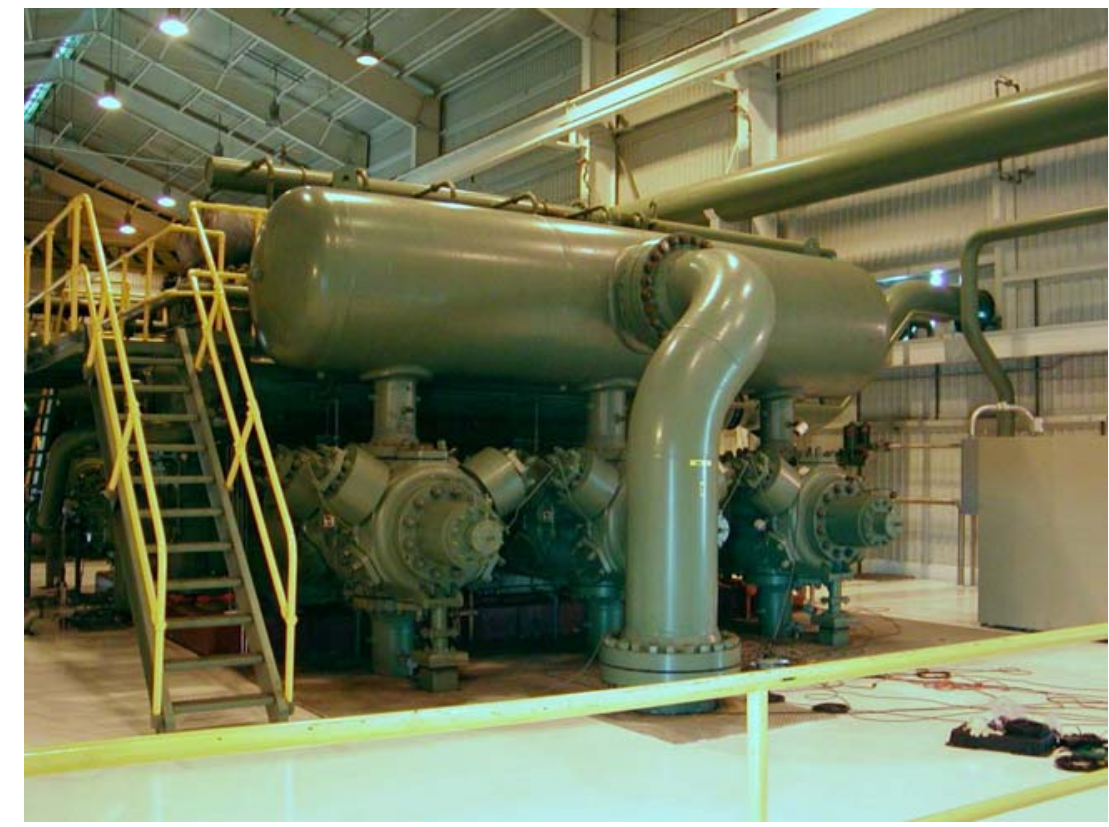

Figure 4-2. Overview Photograph of TCVC10 Unit (Dominion's Groveport Station; April 20, 2005)

\subsection{Summary of SuRVEy TEst Results}

In the HBA-6 tests, the major factor that distinguished performance and pulsations was whether the unit tested was under single-acting or double-acting conditions; single acting led to higher and less stable pulsations and higher losses.

In the TCVC10 tests, the main distinguishing factor for both performance and pulsations was speed. Reducing speed reduced losses because these losses tended to be proportional to the second power of speed. Reducing speed also tended to reduce the highest pulsations, except for the suction lateral line where the reverse was true (probably because reducing speed brought an excitation frequency closer to an acoustic natural frequency in the suction lateral line).

Figure 4-3 compares efficiency values for the two test conditions at each site. The TCVC10 generally has the lowest efficiency; the highest value for the TCVC10 at Groveport (for 270 RPM) approximates the lowest value for the HBA-6 at Bedford, but at $83 \%$ to $84 \%$, it is several points below the $87 \%$ to $88 \%$ high efficiency of the HBA-6. At the nominal speed of 330 RPM, the Groveport efficiency is even lower, dropping below 76\% (the lowest of any tests under the project so far). The fact that the enthalpy based efficiency tracks the DIP based efficiency is encouraging; the one to two points higher for DIP based efficiency may reflect measurement uncertainty or that the enthalpy based efficiency includes more loss contributions than DIP based losses. Both sites reflect potential to increase efficiency closer to benchmark values of $91 \%$ or $92 \%$. 


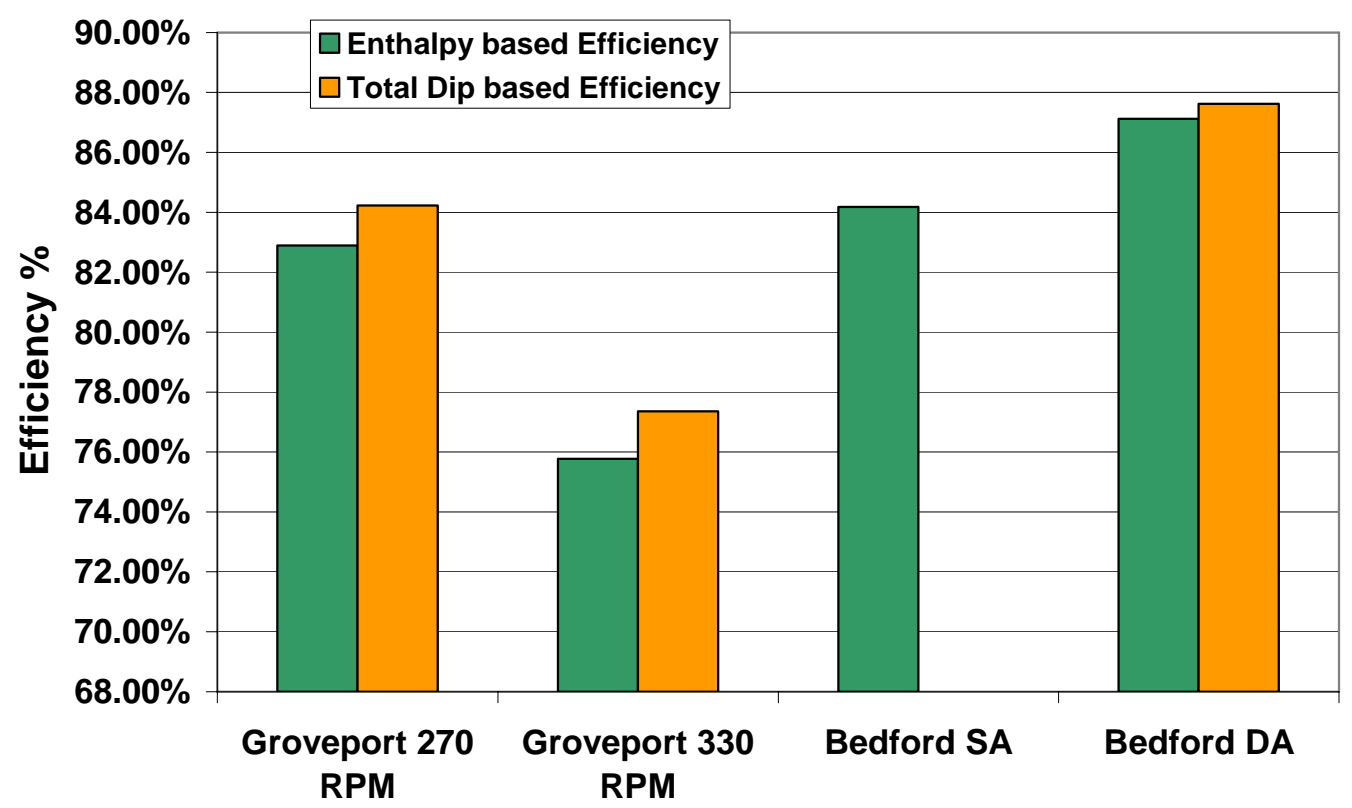

Figure 4-3. Comparison of Enthalpy and DIP Based Efficiency for Bedford and Groveport Stations

Figure 4-4 distinguishes the valve DIP from the total DIP for the two sites, showing in general that losses are about evenly split between valves and installation losses. The inferred non-valve losses from Figure $4-4$ are $8 \%$ and $12.5 \%$ at Groveport for the two speed conditions, and $6.5 \%$ at Bedford for double-acting conditions; a value for non-valve loss is not available at Bedford for single-acting conditions but is likely to be higher than the $6.5 \%$ for double-acting.

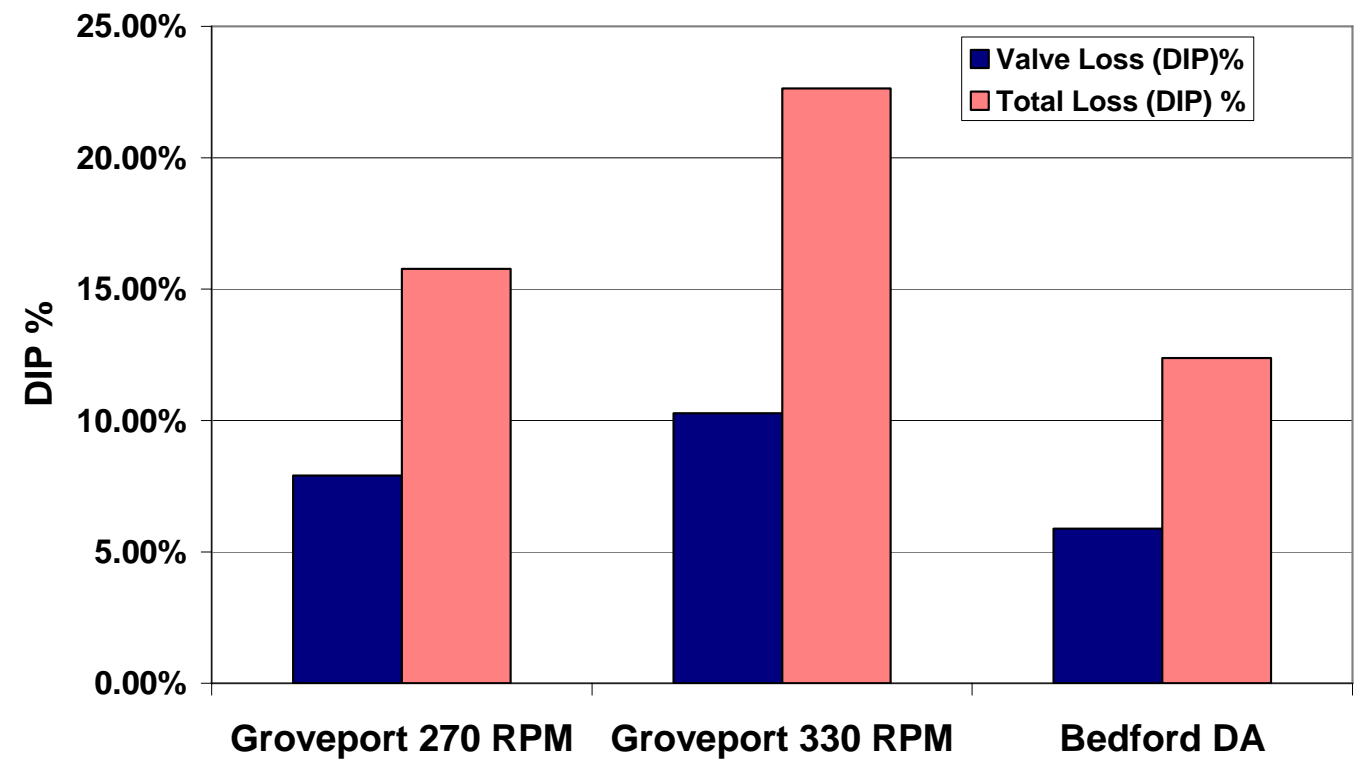

Figure 4-4. Comparison of Valve DIP and Total DIP Loss for Groveport and Bedford Stations 
Thus, while the Groveport results suggest a higher potential for reduction in losses to be achieved by changes outside the cylinder, the need exists to evaluate, through design analysis, the practicality and achievability of loss reduction from specific changes.

Figure 4-5 and Figure 4-6 compare suction and discharge nozzle pulsations associated with each cylinder at Groveport and Bedford. These charts account for the fact that Bedford has four cylinders whereas Groveport has only three. The high pulsation value of around $6 \%$ of line pressure is observed in the Bedford suction and discharge nozzles under single-acting conditions (Cylinder 2 nozzles show the highest pulsations for both suction and discharge). The suction nozzle pulsations for Bedford drop to about $2 \%$ or less under double-acting conditions and are lower than the Groveport suction nozzle pulsations (2.4\% to 4.6\%). However, the highest discharge nozzle pulsations at Bedford under double-acting conditions at $4.7 \%$ (while lower than the $6.2 \%$ under single-acting conditions) remain comparable to the highest discharge nozzle pulsation at Groveport.

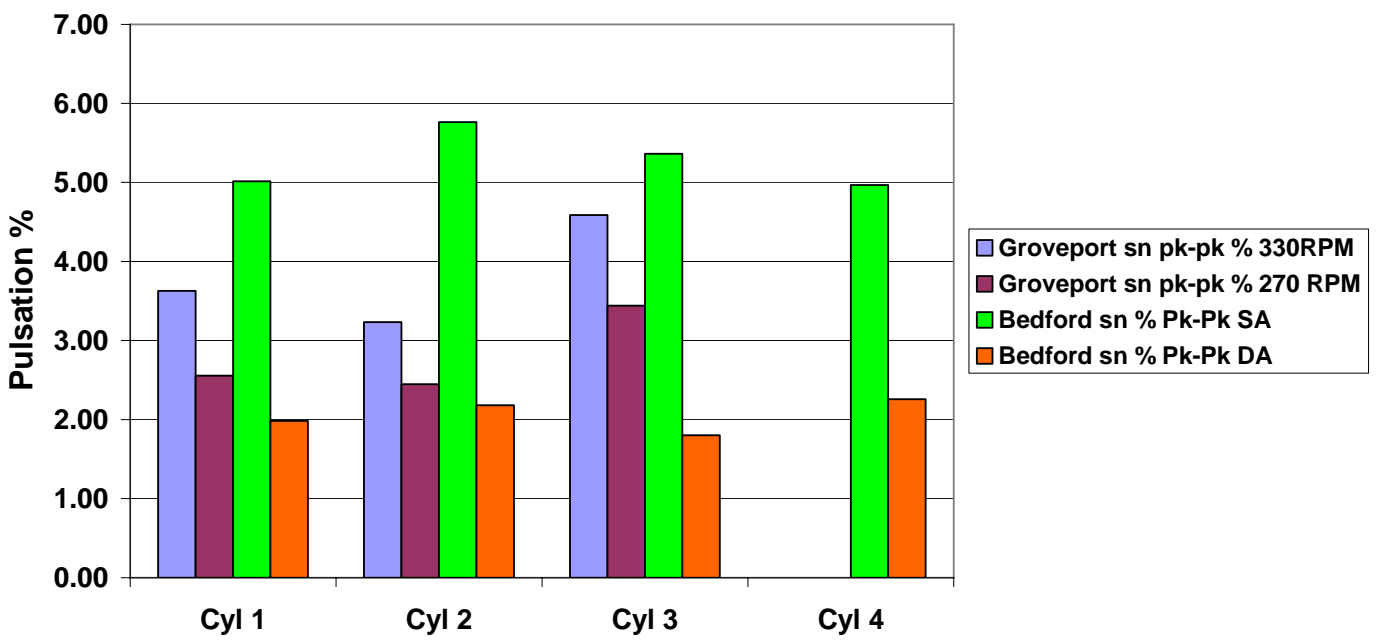

Figure 4-5. Comparison of Suction Nozzle Pulsations; Groveport and Bedford

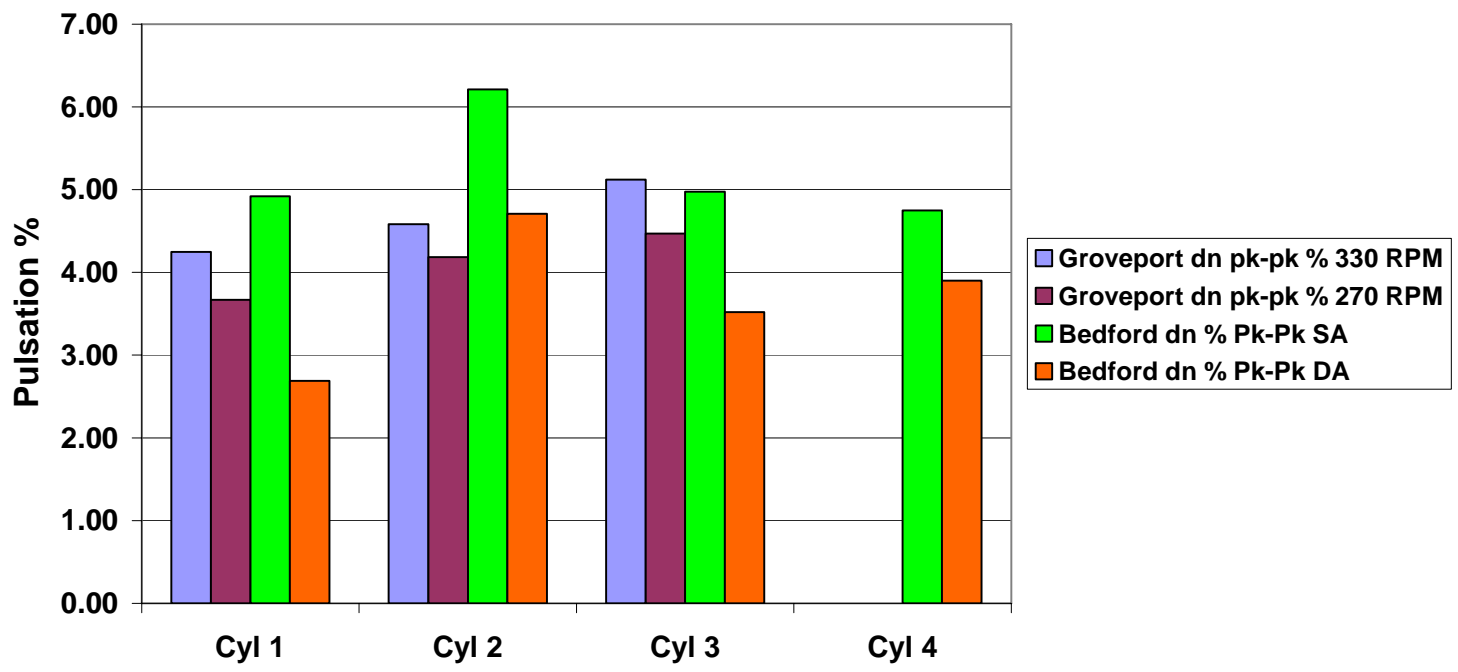

Figure 4-6. Comparison of Discharge Nozzle Pulsations; Groveport and Bedford 
Looking at the suction and discharge lateral pulsations plotted in Figure 4-7 and Figure 4-8 for all cylinders at Groveport and Bedford makes distinctly clear that single-acting conditions at Bedford lead to much higher lateral pulsations (about 3\% of line pressure) than under any other conditions tested (all other plotted values are under 1.77\%). Under doubleacting conditions at Bedford, the high of $1.77 \%$ drops close to the high value of $1.57 \%$ at Groveport.

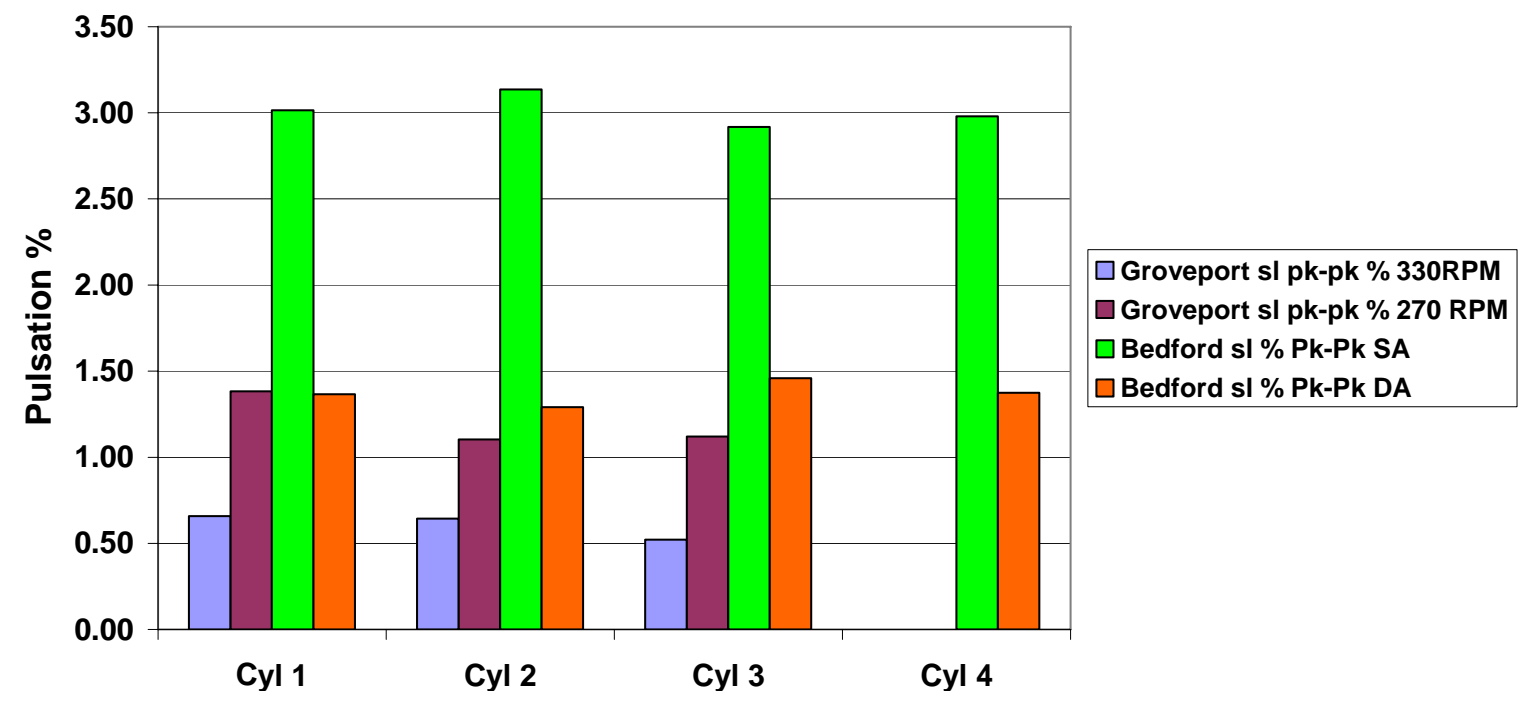

Figure 4-7. Comparison of Suction Lateral Pulsations; Groveport and Bedford

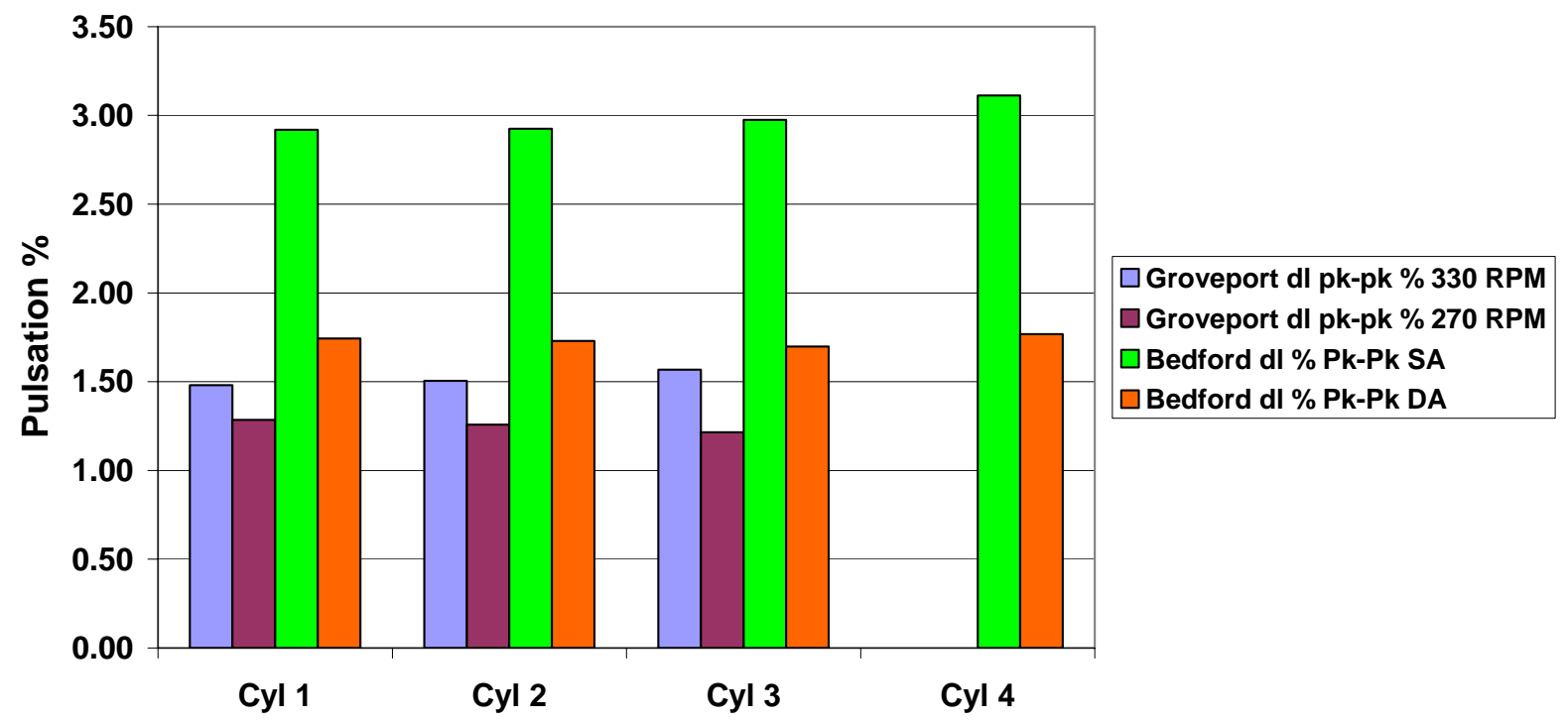

Figure 4-8. Comparison of Discharge Lateral Pulsations; Groveport and Bedford

In summary, both sites offer the potential for increase in thermal efficiency and for reduction in pulsations. The following subsection of this report presents the design analysis performed for the Bedford Station HBA-6. 


\subsection{Design Analysis for the HBa-6 at Bedford Station}

As background to the design analysis, the pulsation related characteristics during operation of the HBA-6 at Bedford Station are summarized as follows:

With multiple units single acting (a common operating condition), there is a strong beating phenomenon, which causes a time variation in horsepower, in speed (and most probably in flow). This results from high, unfiltered, modulation in flow at running frequency.

With multiple units single acting, suction and discharge nozzle pulsation levels are as high as $6 \%$ of line pressure.

With multiple units single acting, the lateral pulsations exceed 3\% on both suction and discharge sides of the compressor.

With multiple units double acting, the beating phenomenon disappears, and the time variation in power and speed drops to levels typically seen on any integral unit.

With multiple units double acting, the suction nozzle pulsations drop to below 2.5\%, discharge nozzle pulsations remain close to $5 \%$.

With multiple units double acting, the lateral pulsations reach about $1.75 \%$ on the discharge side.

Thermal efficiency measured on the day of the tests was about $84 \%$ under single-acting conditions and $87 \%$ under double-acting conditions.

These results strongly suggest the existence of two pulsation related problems: a nozzle resonance and a lack of filtering for flow modulations from the compressor at rotational speed. The $1 \mathrm{X}$ is probably exaggerated by exciting an acoustic resonance.

An acoustic model of the currently installed Bedford compressor manifold piping system has been prepared. Using this model, the GMRC-SwRI IPPS software predicted similar characteristics to those observed under single-acting conditions, as shown by the red data in Figure 4-9. The $1 \mathrm{X}$ response in both suction and discharge laterals reaches 10 to 15 PSI. The ability of the model to predict observed behavior confirms its value as a basis for evaluating alternative solutions in terms of their ability to reduce observed pulsations, as documented below.

The following solution options were evaluated:

- Eliminate or curtail single-acting operation and reduce the speed range

- $\quad$ Add suction nozzle orifices

- $\quad$ Add line orifices

- Install new pulsation bottles

SwRI Project 18.06223; DOE Award No. DE-FC26-02NT41646 


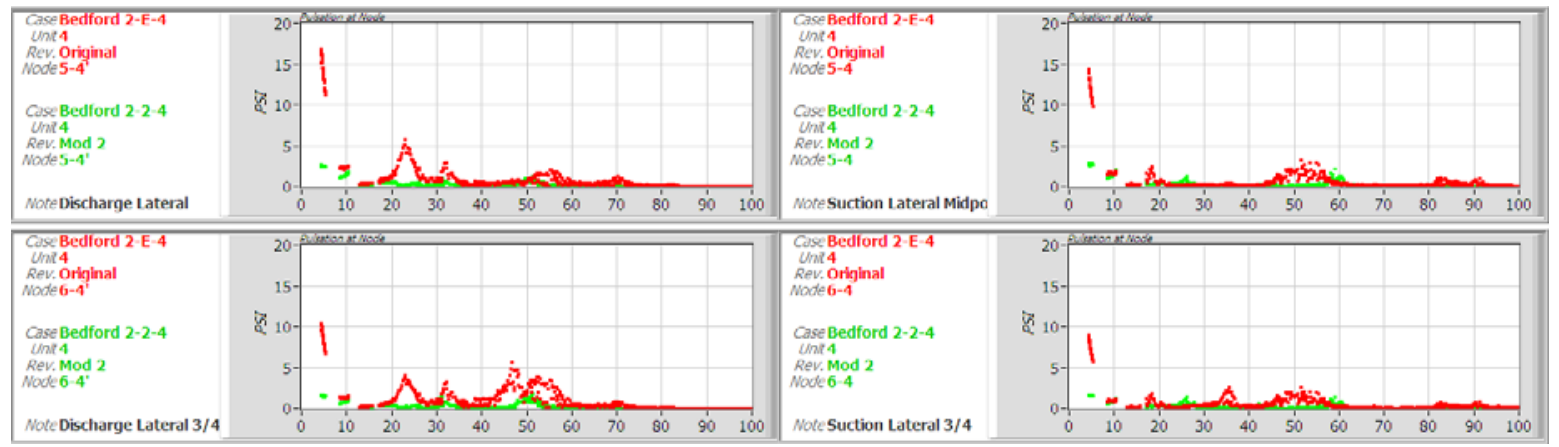

Figure 4-9. Original Pulsations (red) Compared to Pulsations with Modified Bottle (green)

- $\quad$ Shorten the suction nozzles with the existing suction bottle

- $\quad$ Add a Side Branch Absorber to the suction lateral near the existing bottle

The most promising solutions are discussed here.

Figure 4-10 shows the new bottle design evaluated. It has four chambers, one for each cylinder. The chambers are separated by baffles. The lateral piping connects to the two end chambers via a pair of long choke tubes. This configuration acts as an acoustic filter system. It presents some configurational challenges and, as a minimum, would require the discharge nozzles to be offset.

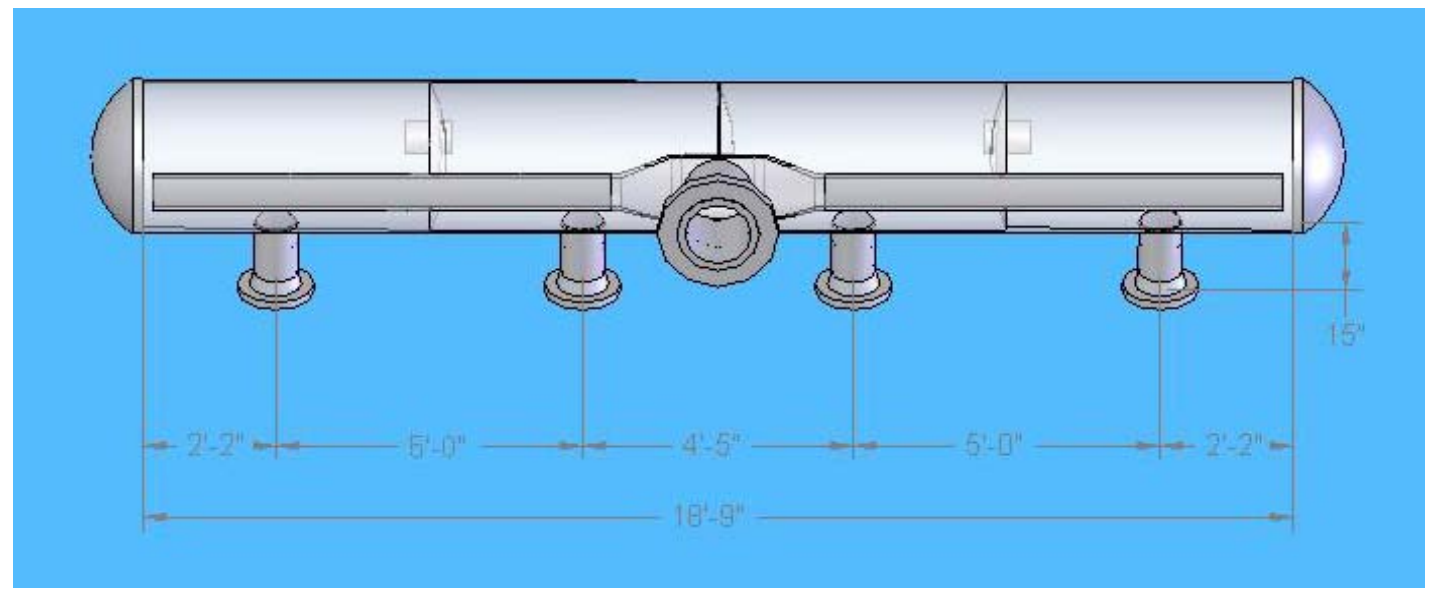

Figure 4-10. Modified Suction Bottle Design

The green data of Figure 4-9, previously referred to, shows how acoustic filtering of this modified bottle reduces predicted pulsations in suction and discharge laterals. It reduces maximum pulsation at $1 \mathrm{X}$ by a factor of 6 to about 2.5 PSI and also reduces discharge nozzle pulsations.

Figure 4-11 illustrates a side branch absorber (SBA), with closed chamber connected to the lateral piping. This adds an acoustic natural frequency to the system, but moves the acoustic natural frequency so $1 \mathrm{X}$ no longer excites it. 

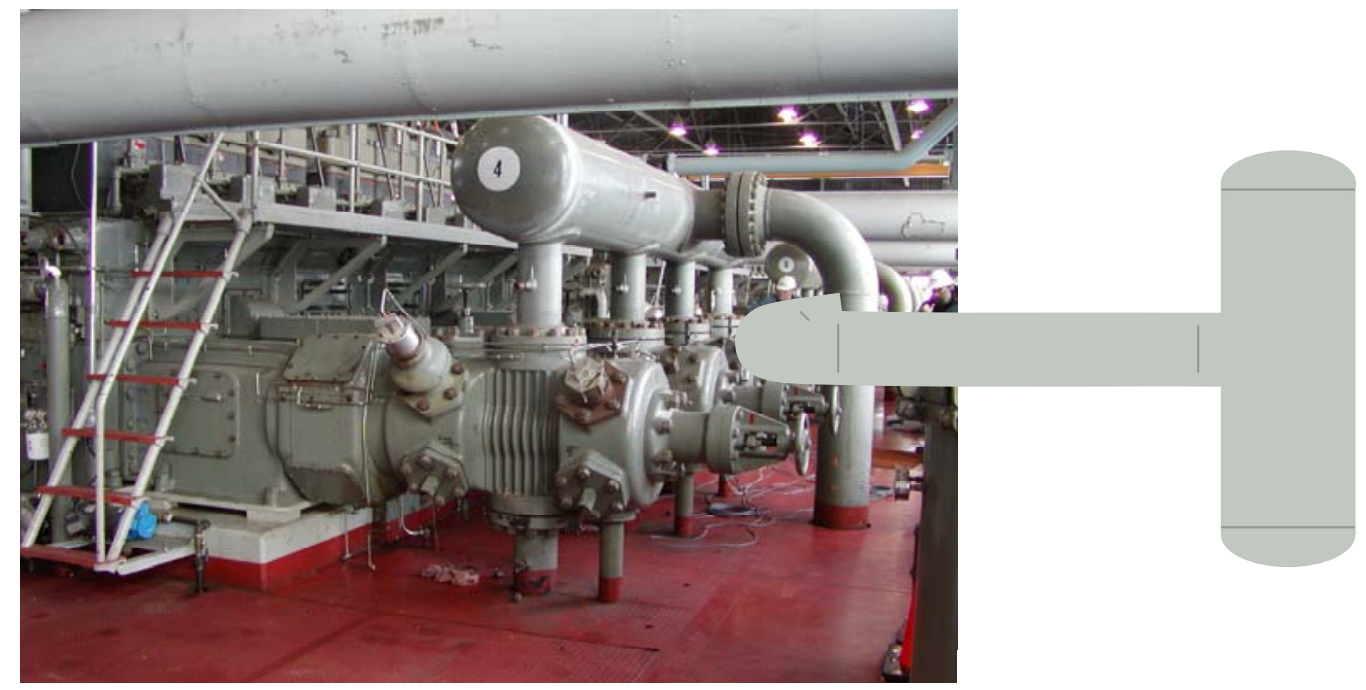

Figure 4-11. Configuration Schematic for Side Branch Absorber

Figure 4-12 shows the predicted benefit of the SBA-it reduces the $1 \mathrm{X}$ pulsations by about a factor of 6 - similar to that achieved by the new bottle design. However, the SBA does not significantly reduce the nozzle pulsations.
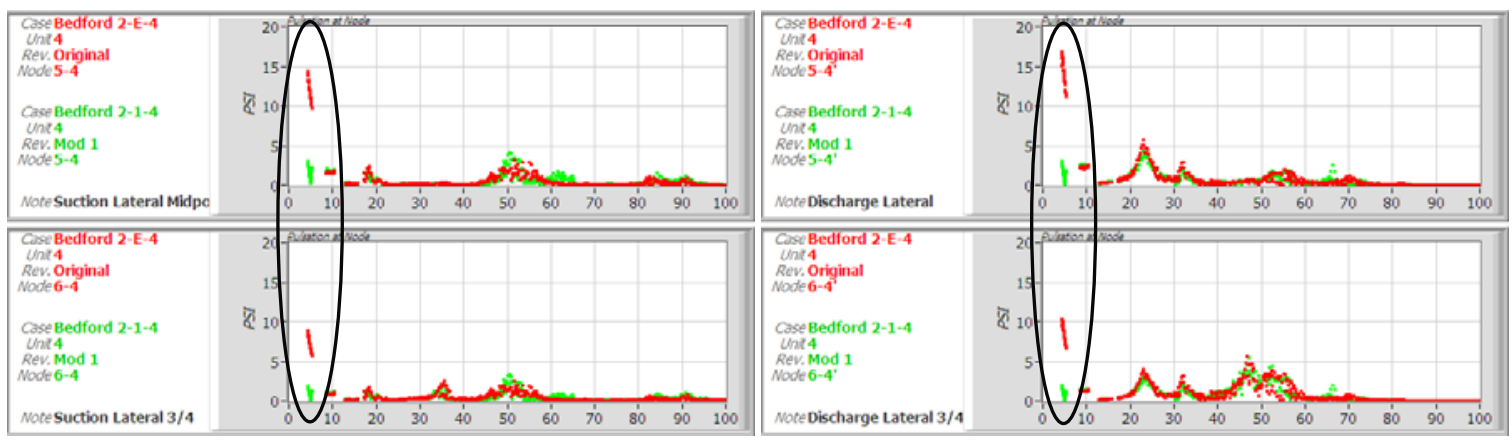

Figure 4-12. Comparison of Original Pulsations with Predicted Pulsations (red) After Addition of Side Branch Absorber (green)

The most effective pair of modifications, which preserves the ability to continue single acting while reducing nozzle pulsations, is to install a new suction bottle with shorter nozzles, in combination with the side branch absorber. This pair of changes will reduce $1 \mathrm{X}$ pulsation levels substantially and also shift the nozzle resonance to a higher frequency with lower excitation levels and will thereby reduce its amplitude of response.

An alternative pair of solutions combines the SBA with a nozzle orifice. This has the advantage of lower capital expenditure, but incurs higher-pressure drop. This option has been selected as a cost-effective solution, after discussions between SwRI and the host company. 


\section{RESULTS AND DISCUSSION: AIR BALANCE TASKS}

\subsection{OVERVIEW AND Background of AIR BaLANCE TASKS}

The Air Balance task was developed to investigate the potential imbalance in trapped air mass, and resulting imbalance of trapped air/fuel ratio, in two-stroke integral compressor engines. Prior field and laboratory measurements of cylinder pressure have shown a spread in the compression pressure between cylinders in all engines tested. The average compression pressure at 20 degrees before top dead center (TDC) for each cylinder of the laboratory GMVH, from over 200 test runs at various operating conditions, is plotted versus air manifold pressure in Figure 5-1. The actual spread in compression pressure and consistency over a variety of operating conditions (speed, load, air/fuel ratio, and spark timing variations) can easily be seen in these figures. Note that Cylinder 3 Left is the lowest.

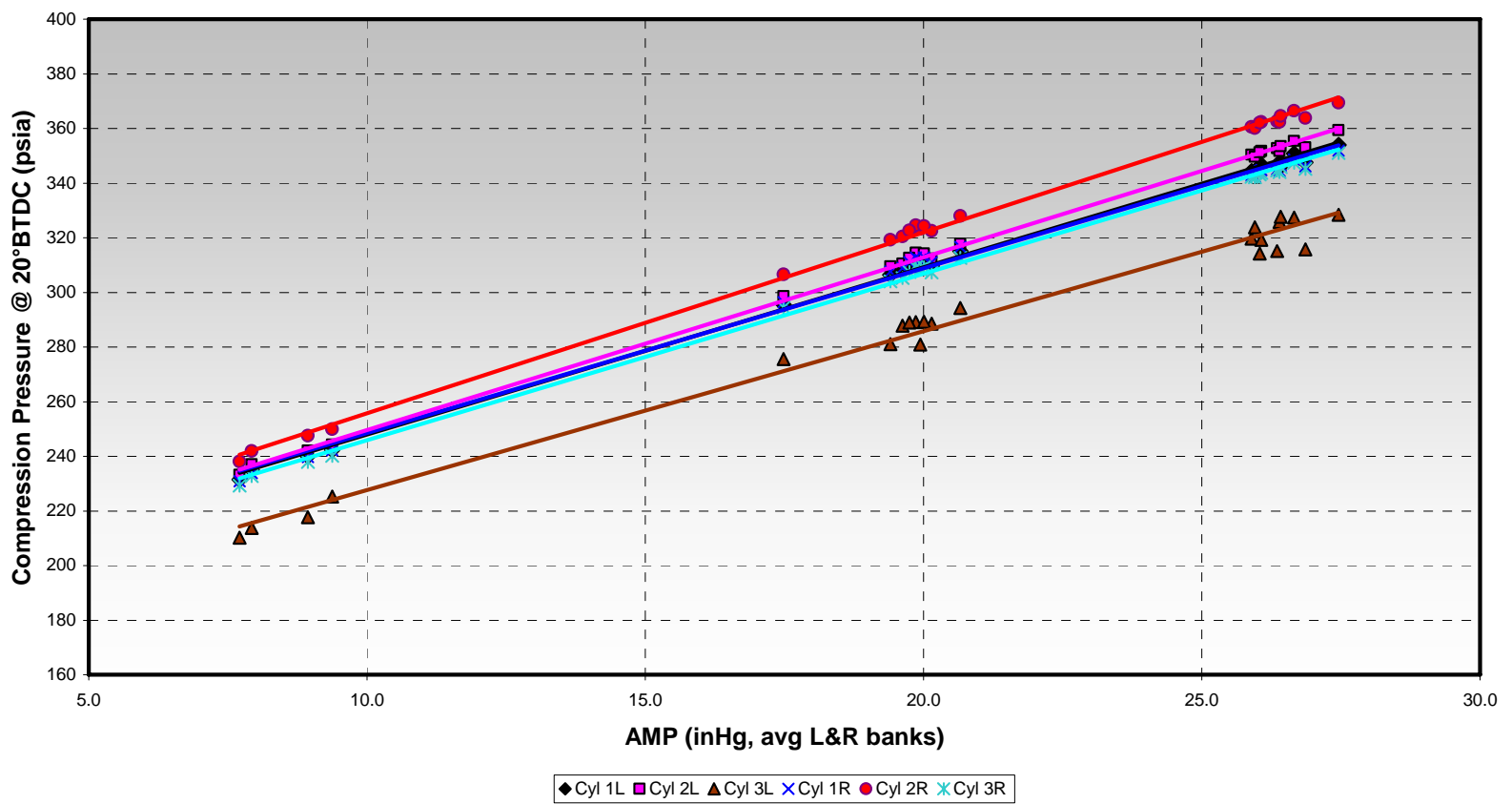

Figure 5-1. 100-Cycle Average Cylinder Pressures at 20 Degrees BTDC versus Air Manifold Pressure

It was theorized that the spread in compression pressures was caused in large part to dynamics in either or both of the intake or exhaust manifolds. This theory was qualitatively based on measurements of high amplitude pressure pulsations in the manifolds and the tendency of the low compression pressure cylinder to be located at the first junction of the intake manifold, nearest the turbocharger outlet. If this theory was correct, then redesigning the manifolds based on actual fluid dynamics of the particular engine should alleviate the spread and create balanced trapped mass between cylinders.

Other factors that could cause this spread in compression pressure relate to cylinder geometry and include mechanical compression ratio, port flow coefficients, and port timings. The uncertainty was to what magnitude each of these factors contributes to the spread, what is 
the likely variation existing in field engines, and whether or not these factors dominate over fluid dynamics effects.

The main objective of the Air Balance tasks is to improve the cylinder-to-cylinder air balance via manifold designs. A secondary objective is to develop a design methodology for designing manifolds and other engine components involved with breathing. To accomplish this task, the fluid dynamics must be understood and quantified. In addition, the cylinder geometry variations must be documented and effects quantified. The Air Balance tasks, therefore, were split into two parts: Conceptual Design and Prototype Evaluation.

\subsection{EngINE TEsting}

Several tests have been pending the completion of engine and test cell re-assembly, which became fully operational this quarter. The first series of tests were to document the change in performance due to the switching of power assemblies between Cylinders 1L and 3L. Prior analysis has shown that the geometric differences (compression ratio, port timing, and port flow coefficient) could account for as much as $50 \%$ to $60 \%$ of the difference in measured spread of compression pressure.

The engine was operated over a range of speeds and loads to generate curves similar to those in Figure 5-1. This new data with the swapped power assemblies is shown in Figure 5-2. The compression pressures from Cylinder 1L are lower as expected. However, the compression pressures from Cylinder 3L increased only marginally. To better illustrate the effect on compression pressure from the component swap, compression pressure data from each cylinder at an air manifold pressure of 20 inHg is plotted in Figure 5-3. This plot shows that the compression pressure for Cylinder $1 \mathrm{~L}$ was reduced by approximately $5 \%$, while the compression pressure for Cylinder 3L increased approximately one percent.

The trends are as confusing as they are helpful. The effect on Cylinder $1 \mathrm{~L}$ was expected, but the minimal change to Cylinder 3L was not as expected. There is apparently still some phenomenon causing Cylinder 3L to achieve the lower compression pressure. As discussed in the previous quarterly report, it was believed that the design of the intake manifold entrance could be affecting the flow balance from the intake into the cylinders. To address this theory, a series of tests with probes located in the intake manifold runners of Cylinders 1L and 3L was developed. The probes used were pitot tubes referenced to the intake manifold log. Figure 5-4 shows the planned measurement locations. This testing has been completed and the data partially analyzed. The average cylinder pressure and pitot tube delta pressure from one of the first measurements are shown in Figure 5-5. The trends indicate a difference in dynamic flow between the test cylinders; however, more analysis is required of all the data before a conclusion can be made. 


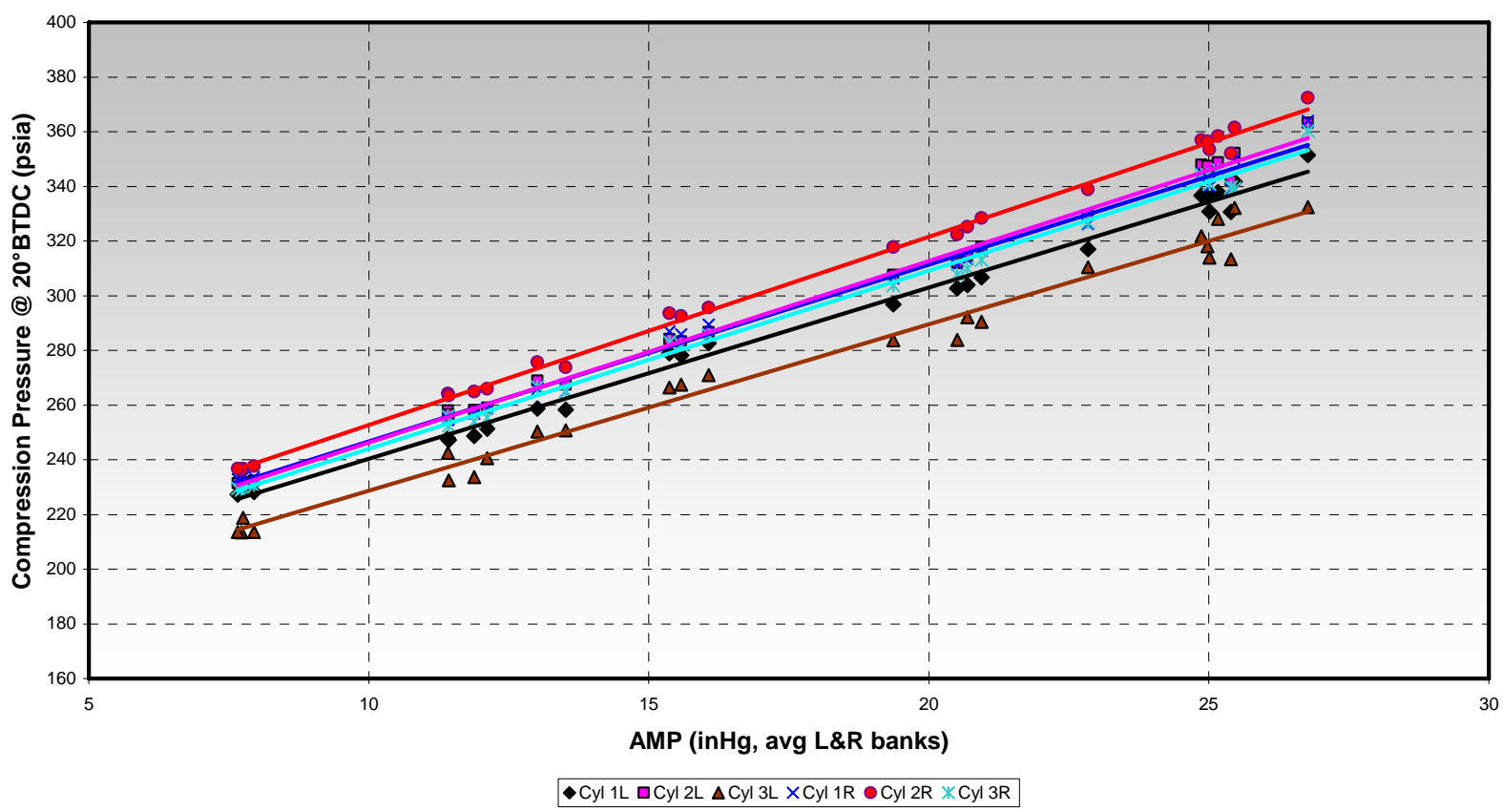

Figure 5-2. 100-Cycle Average Cylinder Pressures at 20 Degrees BTDC versus Air Manifold Pressure - Post Power Assembly Swap

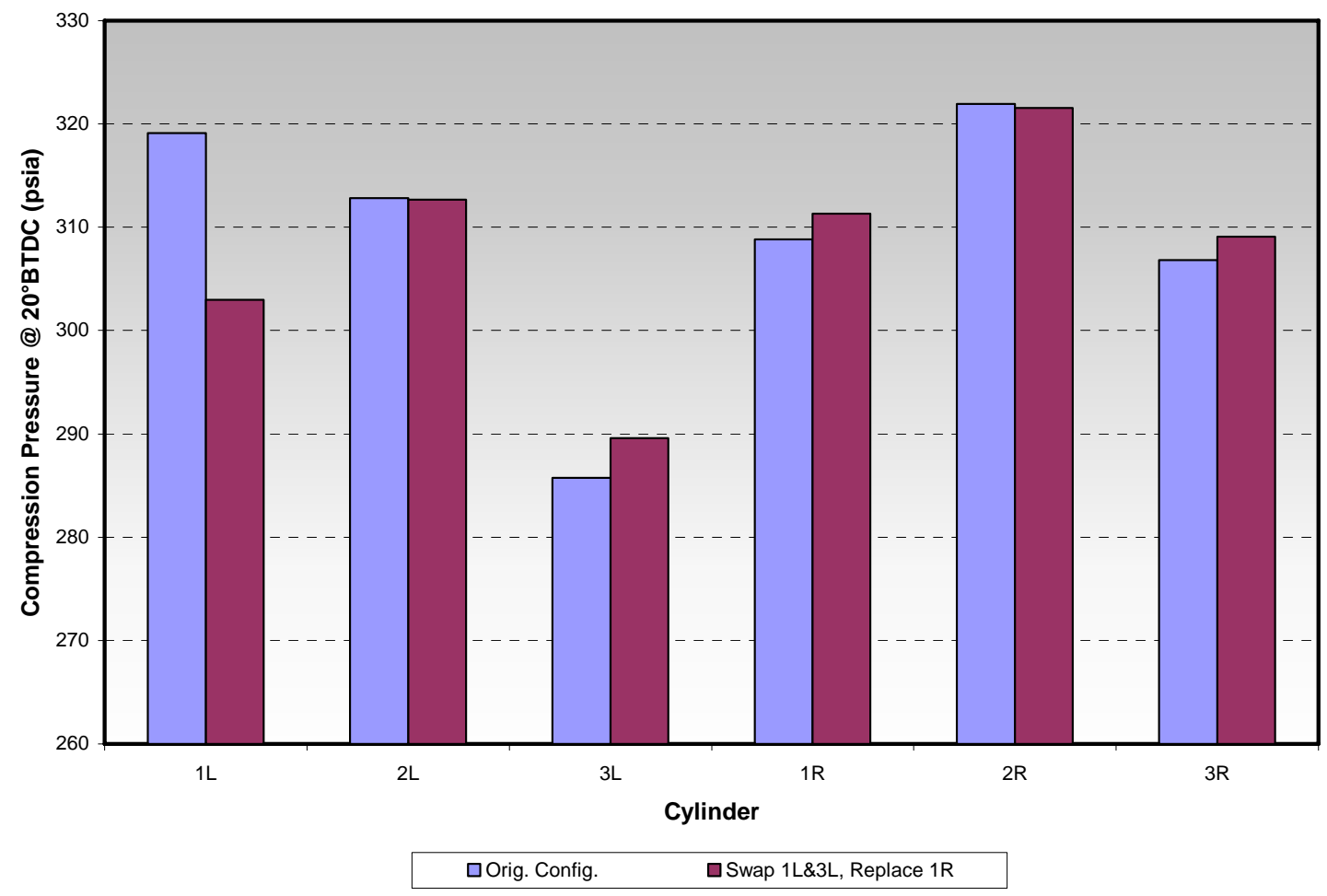

Figure 5-3. Cylinder Pressures at 20 Degrees BTDC for Air Manifold Pressure of $20 \mathrm{inHg}$ - Before and After Power Assembly Swap 

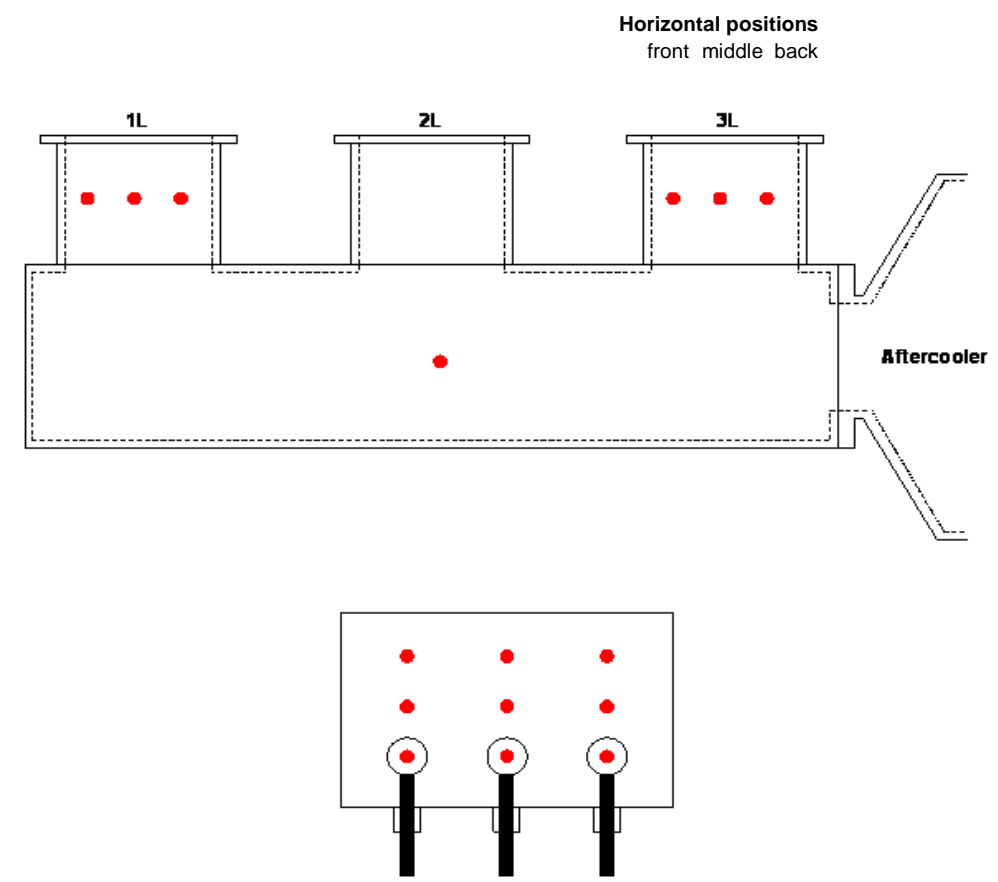

Figure 5-4. Schematic of Intake Manifold Dynamic Flow Measurements

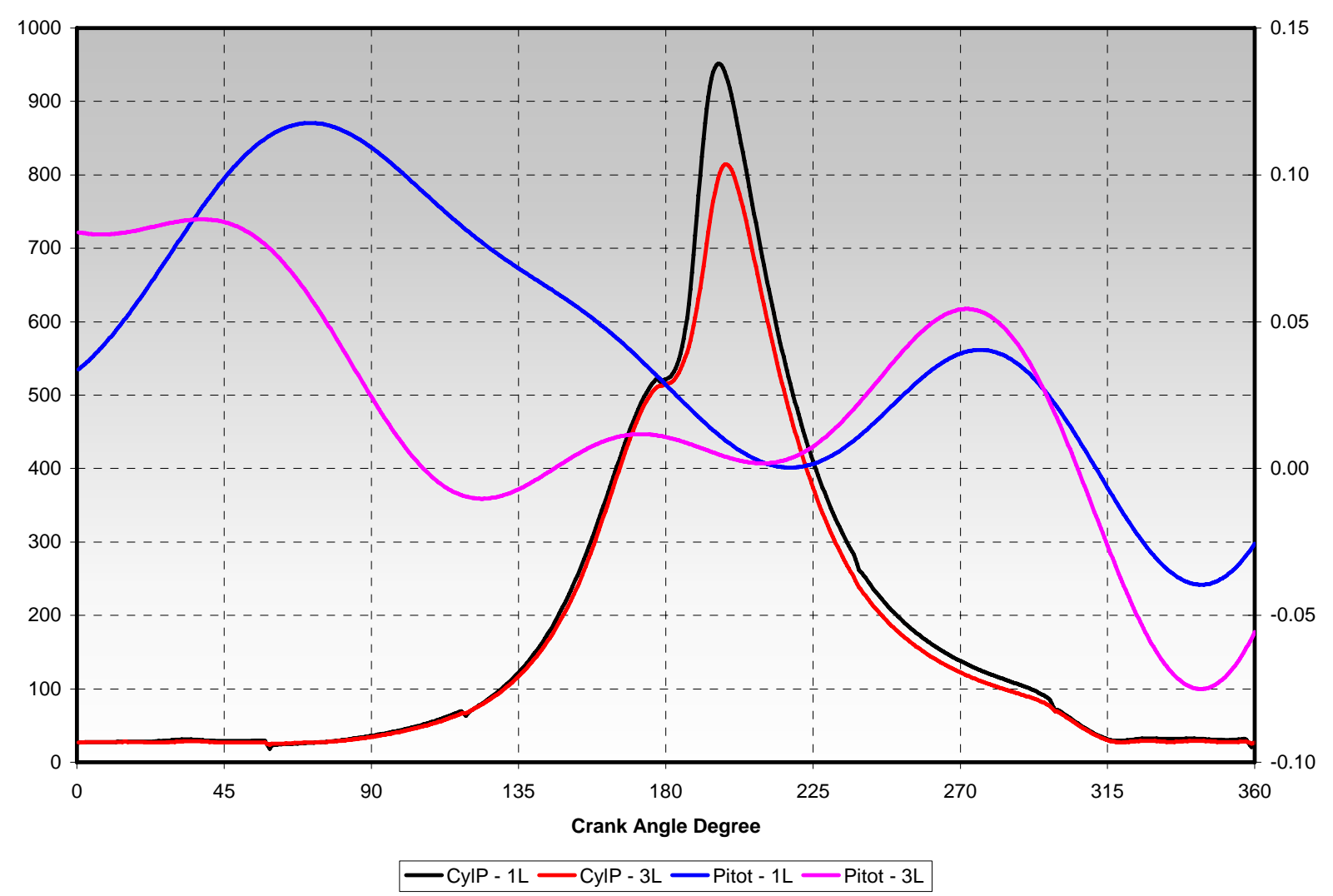

Figure 5-5. Cylinder Pressures and Pitot Delta-Pressure for Cylinders $1 \mathrm{~L}$ and $3 \mathrm{~L}$ at Rated Speed/Load 
Other tests have been performed to ensure data integrity. The data integrity tests included re-calibrating the cylinder pressure transducers and swapping them between cylinders to ensure that sensor variance is not affecting the data. The calibration history of these sensors has shown repeatability of \pm 1 percent since initial installation. The data acquired before and after the transducer swaps show results within \pm 1 percent.

\subsection{Demonstration of Side Branch Absorber}

For the demonstration task on this project, the exhaust side branch absorber (SBA) concept was designed and constructed for testing. The final detailed design features a removable flange to allow for changing the choke tube length for test iterations. A CAD version of the SBA is provided in Figure 5-6. The SBA will be welded to the end of the exhaust manifold log. Fabrication of the SBA has been completed and installation is in progress. Testing of the SBA will involve repeat testing of the many operating conditions tested thus far. Specific focus will be directed toward the exhaust pulsations and effects to scavenging. Additional testing with modified choke tube lengths will be performed contingent on the results with the initial design.

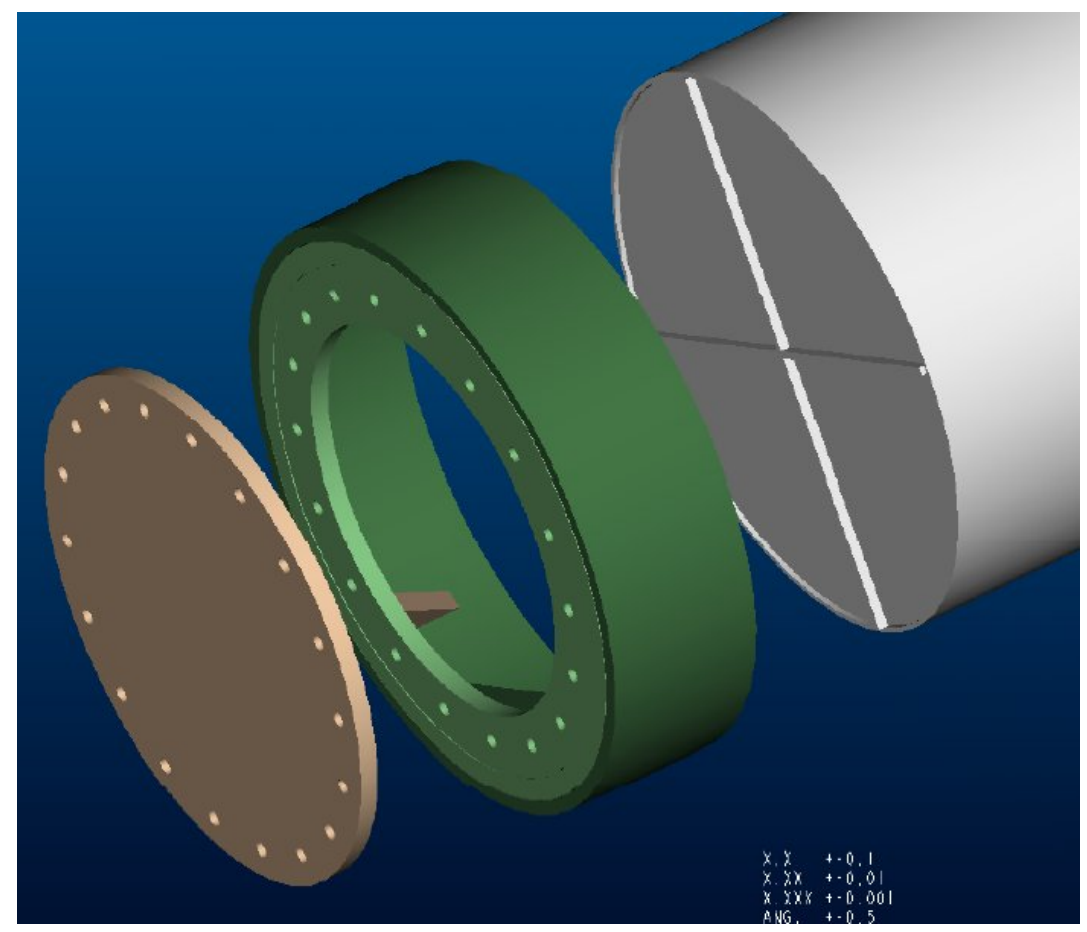

Figure 5-6. Final Design of the Exhaust Side Branch Absorber

\subsection{Future Plans on Air Balance Task}

Future plans on the Air Balance tasks include the following:

- $\quad$ Complete testing and analysis of intake manifold design effects

- $\quad$ Complete topical report

- $\quad$ Complete installation of exhaust SBA and conduct testing 


\section{CONCLUSIONS}

Based on the data presented in Section 4, the following conclusions can be drawn:

1. Survey tests have been performed on engines at two sites: an HBA-6 at Duke's Bedford Station, and a TCVC10 at Dominion’s Groveport Station.

2. Both candidates have the potential for compressor efficiency improvement and resultant improvement in capacity and system efficiency. Both candidates have undesirably high pulsations under some operating conditions.

3. The HBA-6 as tested exhibited an efficiency range from $84 \%$ when single acting, to $87 \%$ when double acting.

4. HBA-6 nozzle pulsations reached over $6 \%$ when single acting, and over $4.5 \%$ when double acting.

5. HBA-6 lateral pulsations exceeded 3\% when single acting and 1.75\% when double acting.

6. The TCVC10 as tested exhibited an efficiency of 76\% at 330 RPM and $83 \%$ at 270 RPM.

7. TCVC10 nozzle pulsations exceeded 5\% at 330 RPM and $4.5 \%$ at 330 RPM.

8. TCVC10 lateral pulsations exceeded $1.5 \%$ at 330 RPM and $1.3 \%$ at 270 RPM.

9. Design analysis has been performed on the HBA-6, using an acoustic model of the suction and discharge piping coupled to the compressor cylinders.

10. This model predicts significant pulsations at $1 \mathrm{X}$ running speed and at the nozzle resonance.

11. The model predictions show that the installation of new bottles would substantially reduce pulsations at running speed and would also reduce nozzle resonance pulsations.

12. The model predicts that installation of a side branch absorber will also reduce pulsations at $1 \mathrm{X}$ running speed but will have limited influence on nozzle resonance pulsations.

13. After discussions between SwRI and the host company, the planned modifications for the Bedford site are to install the side branch absorber together with nozzle orifices.

14. After installation of these modifications, the project will perform tests to quantify performance and pulsation level improvements.

15. A design analysis is also planned shortly for the TCVC10, guided by the test data from the Groveport Station. 
Based on the data presented in Section 5, the following conclusions can be drawn:

1. GMVH testing with swapped power assemblies showed expected directional changes in compression pressure due to geometric differences between components. The magnitude of change, however, was less than expected for Cylinder 3L and not equal to the change that occurred in Cylinder 1L. This trend was consistent over several operating conditions. While these results tend to correlate predicted affects of geometric parameters, the reduced affect on Cylinder 3L suggests there is still some additional phenomenon affecting the pressure-volume relationship.

2. Additional testing of the GMVH is under way to investigate the dynamic flow from the inlet manifold and fuel valves.

3. The exhaust SBA detail design was completed, components procured, and installation for demonstration testing in progress. 


\section{REFERENCES}

[1] Smalley, A. J., Mauney, D. A., and Ash, D. I., (1997) Final Report PR-15-9529, “Compressor Station Maintenance Cost Analysis,” prepared for the Compressor Research Supervisory Committee of PRC International, SwRI Project No. 04-7424.

[2] McKee, R. J., Smalley, A. J., Bourn, G. D., and Young, K. N., (2003) “Detecting Deterioration of Compression Equipment by Normalizing Measured Performance Relative to Expected Performance,” GMRC Gas Machinery Conference (GMC), Salt Lake City, Utah.

[3] Harris, R. E., Edlund, C. E., Smalley, A. J., and Weilbacher, G., (2000) "Dynamic Crank Web Strain Measurements for Reciprocating Compressors,” presented at the GMRC Gas Machinery Conference (GMC), Colorado Springs, Colorado.

[4] Harris, R. E. and Beeson, C. M., (1990) "Channel Resonance Correction for Improved Cylinder Performance and Diagnostic Analyses,” Proceedings, PCRC Fifth Annual Reciprocating Machinery Conference, Nashville, Tennessee. 


\section{LIST OF ACRONYMS AND ABBREVIATIONS}

\begin{tabular}{|c|c|}
\hline AGA3 & Gas Flow Measurement Standard \\
\hline $\mathrm{BDC}$ & Bottom Dead Center \\
\hline BEI & Manufacturer’s Trade Name \\
\hline BHP & Brake Horsepower \\
\hline CPR & Combustion Pressure Ratio \\
\hline $\mathrm{CO}_{2}$ & Carbon Dioxide \\
\hline DAS & Data Acquisition System \\
\hline DIP & Differential Indicated Power \\
\hline DOE & U.S. Department of Energy \\
\hline GMC & Gas Machinery Conference \\
\hline GMRC & Gas Machinery Research Council \\
\hline GMV & Cooper Engine Model \\
\hline GMV6 & Copper Engine Model \\
\hline GMVH & Cooper Engine Model \\
\hline GMW10 & Cooper Engine Model \\
\hline HBA-6 & Clark Engine Model \\
\hline HBA-6T & Clark Engine Model \\
\hline HP & Horsepower \\
\hline $\mathrm{Hz}$ & Hertz \\
\hline ICHP & Indicated Cylinder Horsepower \\
\hline IRV & Instantaneous Rotational Velocity \\
\hline KVG103 & Ingersoll-Rand Engine Model \\
\hline KVS & Ingersoll-Rand Engine Model \\
\hline MMSCFD & Million of Standard Cubic Feet per Day \\
\hline NGK & Manufacturer’s Trade Name \\
\hline $\mathrm{NO}_{\mathrm{x}}$ & Oxides of Nitrogen \\
\hline $\mathrm{O}_{2}$ & Oxygen Molecule \\
\hline PCB & Manufacturer's Trade Name \\
\hline PPM & Parts Per Million \\
\hline PSI & Pounds per Square Inch \\
\hline PSIA & Lb./Sq. Inch Absolute \\
\hline PSIG & Pounds per Square Inch Gauge \\
\hline PV & Pressure-Volume \\
\hline RLM & Rod Load Monitor \\
\hline RPM & Revolutions per Minute \\
\hline SDCM & Strain Data Capture Module \\
\hline SwRI ${ }^{\circledR}$ & Southwest Research Institute ${ }^{\circledR}$ \\
\hline TCF & Trillion Cubic Feet \\
\hline TCV & Family of Dresser Clark engine models \\
\hline TCVC10 & Dresser Clark Engine Model \\
\hline TDC & Top Dead Center \\
\hline TGHP & Theoretical Gas Horsepower \\
\hline TLA6 & Clark Engine Model with Six Power Cylinders \\
\hline $\mathrm{V}-10$ & 10-Cylinder Engine with V Configuration \\
\hline
\end{tabular}

SwRI Project 18.06223; DOE Award No. DE-FC26-02NT41646 